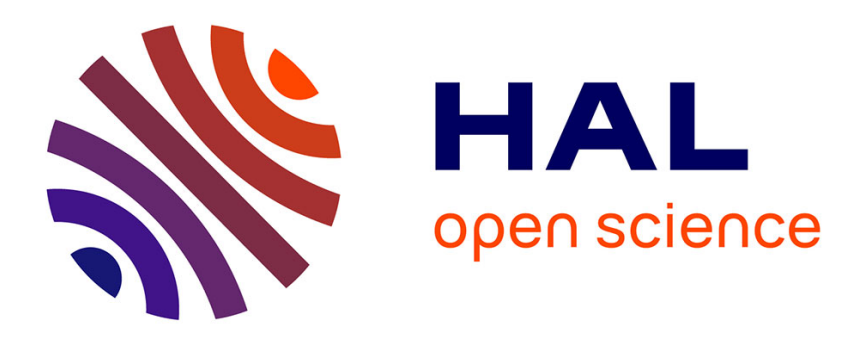

\title{
Modelling the electronic structure of EL2
}

\author{
G.A. Baraff, M. Lannoo
}

\section{To cite this version:}

G.A. Baraff, M. Lannoo. Modelling the electronic structure of EL2. Revue de Physique Appliquée, 1988, 23 (5), pp.817-831. 10.1051/rphysap:01988002305081700 . jpa-00245886

\section{HAL Id: jpa-00245886 https://hal.science/jpa-00245886}

Submitted on 1 Jan 1988

HAL is a multi-disciplinary open access archive for the deposit and dissemination of scientific research documents, whether they are published or not. The documents may come from teaching and research institutions in France or abroad, or from public or private research centers.
L'archive ouverte pluridisciplinaire HAL, est destinée au dépôt et à la diffusion de documents scientifiques de niveau recherche, publiés ou non, émanant des établissements d'enseignement et de recherche français ou étrangers, des laboratoires publics ou privés. 


\title{
Modelling the electronic structure of EL2
}

\author{
G. A. Baraff $\left({ }^{1}\right)$ and M. Lannoo $\left({ }^{2}\right)$ \\ ( ${ }^{1}$ AT \& T Bell Laboratories, Murray Hill, New Jersey 07974-2070, U.S.A. \\ $\left(^{2}\right)$ Laboratoire de Physique des Solides, Institut Supérieur d'Electronique du Nord, 41 boulevard Vauban, \\ 59046 Lille Cedex, France
}

(Reçu le 9 septembre 1987, accepté le 22 octobre 1987)

\begin{abstract}
Résumé. - Les niveaux et énergies d'excitation d'une paire de défauts $\mathrm{As}_{\mathrm{Ga}}-\mathrm{As}_{\mathrm{i}}$ en faible interaction ont été calculés en utilisant une forme analytique de l'énergie introduite par Baraff et Schlüter. Le calcul est effectué de façon à tenir compte, comme l'a proposé Lannoo, de la distorsion Jahn-Teller qui déplace $\mathrm{As}_{\mathrm{i}}$ de son site à haute symétrie. Quand c'est possible nous évaluons les paramètres du modèle à partir des résultats expérimentaux sinon nous utilisons les résultats de calculs selfconsistents par fonctions de Green. Nous trouvons que l'intersticiel $\mathrm{As}_{\mathrm{i}}$ isolé n'a pas d'état d'équilibre susceptible de donner lieu à un spectre R.P.E.. Il présente un niveau donneur hydrogénoïde plus un niveau à deux électrons $\left(\mathrm{As}_{\mathrm{i}}^{+}, \mathrm{As}_{\mathrm{i}}^{3+}\right)$ dans la partie inférieure du gap. Cette structure de niveaux persiste dans la paire qui, en plus des excitations individuelles des défauts, présente une excitation avec transfert de charge $\left(\mathrm{As}_{\mathrm{Ga}}^{0}-\mathrm{As}_{\mathrm{i}}^{+}\right) \rightarrow\left(\mathrm{As}_{\mathrm{Ga}}^{-}-\mathrm{As}_{\mathrm{i}}^{2+}\right)$. L'entité $\mathrm{As}_{\mathrm{Ga}}^{-}$, instable isolément, acquiert une durée de vie plus longue dans la paire. Les calculs supportent la proposition de von Bardeleben et al. qui attribue l'état fondamental de EL2 à la paire $\mathrm{As}_{\mathrm{Ga}}-\mathrm{As}_{\mathrm{i}}$.

Abstract. - The levels and excitation energies of a weakly interacting $\mathrm{As}_{\mathrm{Ga}}-\mathrm{As}_{\mathrm{i}}$ defect pair have been calculated using the model energy functional introduced by Baraff and Schluter. The calculation is performed in a manner which allows the Jahn-Teller relaxation proposed by Lannoo to distort the $A s_{i}$ away from the symmetry site. We evaluate the parameters of the model using experimental information where possible and using the results of self consistent Greens function calculations where no experimental information is available. The isolated $\mathrm{As}_{\mathrm{i}}$ turns out to have no equilibrium state capable of giving rise to an ESR spectrum. It has a shallow donor level plus a two-electron level $\left(\mathrm{As}_{\mathrm{i}}^{+}, \mathrm{As}_{\mathrm{i}}^{3+}\right.$ ) in the lower half gap. This level structure persists in the defect pair, which now contains, in addition to the excitations associated with the individual defects, a charge transfer excitation in which $\left(\mathrm{As}_{\mathrm{Ga}}^{0}-\mathrm{As}_{\mathrm{i}}^{+}\right) \rightarrow\left(\mathrm{As}_{\mathrm{G}_{\mathrm{a}}^{-}}^{-}-\mathrm{As}_{\mathrm{i}}^{2+}\right)$. The species $\mathrm{As}_{\mathrm{Ga}}^{-}$, which is unstable in isolation, becomes longer lived as a component of the defect pair. The calculations support the proposal of von Bardeleben et al. that the ground state of the metastable defect EL2 is, in fact, this defect pair.
\end{abstract}

\section{Introduction.}

There seems to be a growing, but far from unanimous, consensus that EL2 (a metastable native donor defect in GaAs) [1] is really an arsenic antisite $\left(\mathrm{As}_{\mathrm{Ga}}\right)$ with an arsenic interstitial $\left(\mathrm{As}_{\mathrm{i}}\right)$ near by. The suggestion was first put forth by von Bardeleben et al. [2] and they have developed it in a series of papers [3-7]. The mechanism they have most recently proposed [7] for the photoinduced [8] metastability is that optical absorption takes place in the complex $\left(\mathrm{As}_{\mathrm{Ga}}^{0}-\mathrm{As}_{\mathrm{i}}^{+}\right)$, resulting in an internal charge transfer excitation to the complex $\left(\mathrm{As}_{\mathrm{Ga}}^{-}-\mathrm{As}_{\mathrm{i}}^{2+}\right)$. The resulting Coulomb attraction causes the relatively mobile $\mathrm{As}_{\mathrm{i}}$ to move closer to the $\mathrm{As}_{\mathrm{Ga}}$, changing the structure of the defect pair so much that it no longer responds to light or to deep level transient spectroscopy (DLTS).

The $A s_{\mathrm{Ga}}-\mathrm{As}_{\mathrm{i}}$ pair was soon observed by Spaeth [9] using electron spin resonance (ESR) and optical detection of nuclear double resonance (ODENDOR). He was able to determine that the $A s_{i}$ is located near the $T_{d}$ interstitial site two bond lengths from the $\mathrm{As}_{\mathrm{Ga}}$ along the $\langle 111\rangle$ direction. Photoquenching experiments on the resonance signals strengthen the identification of this defect pair with EL2.

It is known that the transition from the normal to the metastable state of EL2 occurs with no change in charge [8]. It has long been accepted that this 
transition occurs in the neutral state, but that belief is based on indirect evidence and has very recently been challenged by Bourgoin and Lannoo [6]. This is a matter of controversy that will have to be studied experimentally.

On the theoretical side, Baraff and Schluter [10] have recently calculated the electronic structure and relative stability of this defect pair in an attempt to understand more about the transition to the metastable state. In their calculation, they made explicit use of the idea that the transition occurs in the neutral state. One of the consequences of their study was that if this defect pair really is EL2, then the isolated $\mathrm{As}_{\mathrm{i}}$ (which has not yet been seen) has to have an acceptor level lying slightly above the main donor level of EL2, and this acceptor level will be a part of the level structure of the $A s_{\mathrm{Ga}}-\mathrm{As}_{\mathrm{i}}$ pair. In their study, the effects of Jahn Teller relaxation were ignored.

Very recently, two things have happened which directly impact on our understanding of this defect. The first is that reinterpretation of the ODENDORESR results has allowed Meyer et al. to conclude that there is no unpaired electron on the $A s_{i}$ when they observe the ESR-ODENDOR signal of the $\mathrm{As}_{\mathrm{Ga}}$ [11]. The second is Lannoo's study [12] of the role that Jahn-Teller distortions play in altering the $T_{2}$ levels of a defect with nominal $T_{d}$ symmetry. The arsenic interstitial is one of these [13]. Lannoo showed that under some conditions, it might be possible for such a defect to have neither levels in the gap nor any resonance spectrum. This might explain why the isolated $A s_{i}$ has not yet been seen.

The purpose of the present work is to extend the earlier calculations by Baraff and Schluter [10] and by Lannoo [12] in four ways : 1 . To estimate the Jahn-Teller relaxation energy of $\mathrm{As}_{\mathrm{i}}$. 2. To include the effects of this specific relaxation energy on the level structure of the $A s_{i}$. 3. To do the same for the level structure of the interacting pair. 4. To discuss the EL2 properties in terms of this model.

The plan of this paper is as follows : in section 2 , we review the model energy for the defect pair. This is basically the same energy functional as was used by Baraff and Schluter [10] except for allowing the Jahn-Teller distortion. We estimate the Jahn-Teller energies in section 3 . In section 4 , we discuss the level structure of the isolated $\mathrm{As}_{\mathrm{i}}$ and in section 5, the level structure and excitation energies of the pair. Section 6 contains the comparison with experiment, both for the purpose of determining the parameters of the model and discussing what they imply for the understanding of EL2. Section 7 summarizes our findings, discusses how they are affected by uncertainties in the model, and concludes by listing some of the problems concerning EL2 which are still left unresolved.

\section{Model for the defects in weak interaction.}

The model to be used here is basically the same one used and justified in reference [10], with one difference : it is now necessary to consider states of the isolated $\mathrm{As}_{\mathrm{i}}$ with fewer electrons than were considered earlier. This will require slight changes in notation. Let us review the basic ideas and notation.

2.1 THE ISOlAted ANTISITE. - In order to describe the energy and charge of the isolated antisite, we specify $N_{\mathrm{A}}^{\mathrm{a}}=0,1,2$, the occupation number for its $\mathrm{A}_{1}$ state and $N_{\mathrm{T}}^{\mathrm{a}}=0,1$, the occupation number for its $\mathrm{T}_{2}$ state. The charge of the antisite is

$$
Q_{\mathrm{a}}=-\left(N_{\mathrm{A}}^{\mathrm{a}}+N_{\mathrm{T}}^{\mathrm{a}}-2\right)
$$

and its energy, expanded to second order in the occupation number, is

$$
\begin{aligned}
E_{\mathrm{a}}\left(N_{\mathrm{A}}^{\mathrm{a}}, N_{\mathrm{T}}^{\mathrm{a}}\right)=E_{\mathrm{a}}^{0}+N_{\mathrm{A}}^{\mathrm{a}} \varepsilon_{\mathrm{A}}^{\mathrm{a}}+N_{\mathrm{T}}^{\mathrm{a}} \varepsilon_{\mathrm{T}}^{\mathrm{a}}+ \\
+\frac{1}{2}\left[\left(N_{\mathrm{A}}^{\mathrm{a}}\right)^{2} U_{\mathrm{A}}^{\mathrm{a}}+2 N_{\mathrm{A}}^{\mathrm{a}} N_{\mathrm{T}}^{\mathrm{a}} U_{\mathrm{X}}^{\mathrm{a}}+\left(N_{\mathrm{T}}^{\mathrm{a}}\right)^{2} U_{\mathrm{T}}^{\mathrm{a}}\right] .
\end{aligned}
$$

The three $U$ terms are basically measures of electron repulsion. The $A_{1}$ and $T_{2}$ wave functions are not too dissimilar. For this reason, we set all the $U$ terms equal to each other, i.e., $U_{\mathrm{A}}^{\mathrm{a}}=U_{\mathrm{X}}^{\mathrm{a}}=U_{\mathrm{T}}^{\mathrm{a}} \equiv U^{\mathrm{a}}$. The overall additive energy $E_{\mathrm{a}}^{0}$ plays no role and can be ignored. Thus, the energy of the isolated antisite is taken to be

$$
\begin{aligned}
E_{\mathrm{a}}\left(N_{\mathrm{A}}^{\mathrm{a}}, N_{\mathrm{T}}^{\mathrm{a}}\right)=N_{\mathrm{A}}^{\mathrm{a}} \varepsilon_{\mathrm{A}}^{\mathrm{a}}+ & N_{\mathrm{T}}^{\mathrm{a}} \varepsilon_{\mathrm{T}}^{\mathrm{a}}+ \\
& +\frac{1}{2}\left(N_{\mathrm{A}}^{\mathrm{a}}+N_{\mathrm{T}}^{\mathrm{a}}\right)^{2} U^{\mathrm{a}} .
\end{aligned}
$$

Numerical values of the parameters, agreeing with both theory [13, 14] and experiment as explained in reference [10] are

$$
\begin{aligned}
U^{\mathrm{a}} & =0.23 \mathrm{eV} \\
\varepsilon_{\mathrm{T}}^{\mathrm{a}}-\varepsilon_{\mathrm{A}}^{\mathrm{a}} & =1.04 \mathrm{eV}
\end{aligned}
$$

As in reference [10] we shall allow $\varepsilon_{A}^{a}$ to be determined by comparison with experiment on the assumption that the interacting pair is EL2.

\subsection{The isolated INTERSTITIAL. - We allow the} isolated interstitial to move along the antibonding $\langle 111\rangle$ direction through any unit cell. We designate its position along that line by $R$, a dimensionless coordinate whose unit value corresponds to one half the nearest neighbour spacing. As shown in figure 1, at $R=0$ the interstitial is at the $\mathrm{T}_{\mathrm{d}}$ site having four arsenic nearest neighbours. At $R=2$, the interstitial is at the $T_{d}$ site having four gallium nearest neighbours. At $R=1$, the interstitial is at the centre of a puckered hexagon with three nearest neighbour gallium, and three nearest neighbour arsenic. At $R=4$, the interstitial is at that gallium site which 


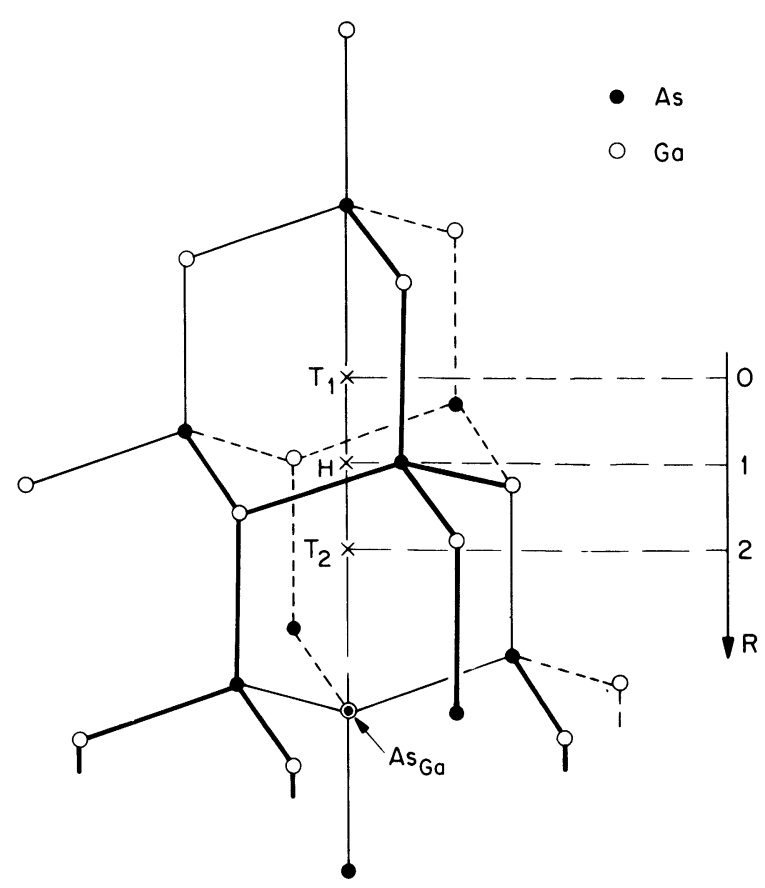

Fig. 1. - Atomic arrangement of the $\mathrm{As}_{\mathrm{Ga}}-\mathrm{As}_{\mathrm{i}}$ defect pair. The $A s_{G a}$ is located at a Ga site and the $A s_{i}$ is located near the site of $T_{d}$ symmetry having four arsenic nearest neighbours. Jahn-Teller distortion allows the $\mathrm{As}_{\mathrm{i}}$ to move in a direction away from any of its four nearest neighbours. In this paper, we consider its motion in the direction towards the $\mathrm{As}_{\mathrm{Ga}}$. The coordinate $R$ measures its displacement.

will later be occupied by the $\mathrm{As}_{\mathrm{Ga}}$ defect. Its distance from that site for a general $R<4$ is

$$
r=(4-R) b / 2
$$

where $b$ is the distance between nearest neighbour atoms.

At $R=0$ and at $R=2$, the system has $\mathrm{T}_{\mathrm{d}}$ symmetry, and the interstitial gap state has $\mathrm{T}_{2}$ symmetry [13]. At other values of $R$, the symmetry drops to $\mathrm{C}_{3 \mathrm{v}}$, and the $\mathrm{T}_{2}$ manifold splits into an $\mathrm{A}$ and an $\mathrm{E}$. We can describe the isolated interstitial by specifying $N_{\mathrm{A}}^{\mathrm{i}}=0,1,2$, (the occupation number of the $\mathrm{A}$ manifold) $N_{\mathrm{E}}^{\mathrm{i}}=0,1, \ldots, 4$, (the occupation number of its $\mathrm{E}$ manifold) and $R$. The charge of the interstitial is

$$
Q_{\mathrm{i}}=-\left(N_{\mathrm{A}}^{\mathrm{i}}+N_{\mathrm{E}}^{\mathrm{i}}-3\right)
$$

and its energy, expanded to second order and ignoring the differences between $U_{\mathrm{A}}^{\mathrm{i}}, U_{\mathrm{X}}^{\mathrm{i}}$ and $U_{\mathrm{E}}^{\mathrm{i}}$, is

$$
\begin{aligned}
E_{\mathrm{i}}\left(N_{\mathrm{A}}^{\mathrm{i}},\right. & \left.N_{\mathrm{E}}^{\mathrm{i}}, R\right)=E_{\mathrm{i}}^{0}(R)+N_{\mathrm{A}}^{\mathrm{i}} \varepsilon_{\mathrm{A}}^{\mathrm{i}}(R)+ \\
& +N_{\mathrm{E}}^{\mathrm{i}} \varepsilon_{\mathrm{E}}^{\mathrm{i}}(R)+\frac{1}{2}\left(N_{\mathrm{A}}^{\mathrm{i}}+N_{\mathrm{E}}^{\mathrm{i}}\right)^{2} U_{\mathrm{i}}(R) .
\end{aligned}
$$

As in reference [10], we expect a negligibly small dependence of $U_{\mathrm{i}}$ on $R$ and we shall take

$$
U_{\mathrm{i}}(R) \equiv U^{\mathrm{i}}=0.33 \mathrm{eV}
$$

namely, equal to the calculated value [13], there being no experimental value with which to compare. Recognizing that $\varepsilon_{\mathrm{A}}^{\mathrm{i}}$ and $\varepsilon_{\mathrm{E}}^{\mathrm{i}}$ differ because of crystal field splitting of the $T_{2}$ manifold (where the $E$ state usually rises half as much as the A state drops) we write

$$
\begin{aligned}
& \varepsilon_{\mathrm{E}}^{\mathrm{i}}(R)=\varepsilon_{\mathrm{T}}^{\mathrm{i}}(R)+\frac{1}{2} \alpha(R) \\
& \varepsilon_{\mathrm{A}}^{\mathrm{i}}(R)=\varepsilon_{\mathrm{T}}^{\mathrm{i}}(R)-\alpha(R) .
\end{aligned}
$$

The discussion in reference [10] (last paragraph of the first column on page 6161), suggests that, to within $0.09 \mathrm{eV}$, we can neglect the $R$ dependence of $\varepsilon_{\mathrm{T}}^{\mathrm{i}}$. Under this further approximation, we have the energy (2.6) reduced to the form

$$
\begin{aligned}
& E_{\mathrm{i}}\left(N_{\mathrm{A}}^{\mathrm{i}}, N_{\mathrm{E}}^{\mathrm{i}}, R\right)=E_{\mathrm{i}}^{0}(R)+\left(N_{\mathrm{A}}^{\mathrm{i}}+N_{\mathrm{E}}^{\mathrm{i}}\right) \varepsilon_{\mathrm{T}}^{\mathrm{i}}- \\
& -\left(N_{\mathrm{A}}^{\mathrm{i}}-\frac{1}{2} N_{\mathrm{E}}^{\mathrm{i}}\right) \alpha(R)+\frac{1}{2}\left(N_{\mathrm{A}}^{\mathrm{i}}+N_{\mathrm{E}}^{\mathrm{i}}\right)^{2} U^{\mathrm{i}} .
\end{aligned}
$$

As in reference [10], we shall allow $\varepsilon_{\mathrm{T}}^{\mathrm{i}}$ to be determined by comparison with experiment on the assumption that the interacting pair is EL2.

2.3 The TOTAL ENERGY. - It turned out [10] that in the range $0<R<1$ of interest here, the two defects are sufficiently far apart that the dominant interaction is the Coulomb energy

$$
V\left(N_{\mathrm{A}}^{\mathrm{a}}, N_{\mathrm{T}}^{\mathrm{a}}, N_{\mathrm{A}}^{\mathrm{i}}, N_{\mathrm{E}}^{\mathrm{i}}, R\right)=Q_{\mathrm{a}} Q_{\mathrm{i}} / \varepsilon r .
$$

Thus, for the total energy of the system, we shall use

$$
\begin{array}{r}
E\left(N_{\mathrm{A}}^{\mathrm{a}}, N_{\mathrm{T}}^{\mathrm{a}}, N_{\mathrm{A}}^{\mathrm{i}}, N_{\mathrm{E}}^{\mathrm{i}}, R\right)=E_{\mathrm{a}}\left(N_{\mathrm{A}}^{\mathrm{a}}, N_{\mathrm{T}}^{\mathrm{a}}\right)+ \\
+E_{\mathrm{i}}\left(N_{\mathrm{A}}^{\mathrm{i}}, N_{\mathrm{E}}^{\mathrm{i}}, R\right)+Q_{\mathrm{a}} Q_{\mathrm{i}} / \varepsilon r
\end{array}
$$

where

$$
\begin{aligned}
& Q_{\mathrm{a}}=2-N_{\mathrm{A}}^{\mathrm{a}}-N_{\mathrm{T}}^{\mathrm{a}} \\
& Q_{\mathrm{i}}=3-N_{\mathrm{A}}^{\mathrm{i}}-N_{\mathrm{E}}^{\mathrm{i}} .
\end{aligned}
$$

This expression leaves out an energy that is needed to account for the very existence of the defect pair, namely, the binding energy that keeps it from dissociating into an isolated $\mathrm{As}_{\mathrm{Ga}}$ plus an isolated $\mathrm{As}_{\mathrm{i}}$.

\section{Estimation of the Jahn-Teller energy for the isolated interstitial.}

Since $R=0$ and $R=2$ are both configurations of $\mathrm{T}_{\mathrm{d}}$ symmetry where the $\mathrm{A}$ manifold and the $\mathrm{E}$ manifold are degenerate, $\alpha(R)=0$ at both $R=0$ 
and $R=2$. One simple, arbitrary, smooth functional form allowing for this is

$$
\alpha(R)=\frac{2 F}{\pi} \sin \frac{\pi R}{2} .
$$

The factor of $\frac{2}{\pi}$ has been included so that in the $R \rightarrow 0$ limit, we have

$$
\varepsilon_{\mathrm{A}}^{\mathrm{i}}(R)=\varepsilon_{\mathrm{T}}^{\mathrm{i}}-F R
$$

in accord with the usual Jahn-Teller notation.

Now consider $E_{\mathrm{i}}^{0}(R)$. Experimental [11] and theoretical [10] evidence suggest minima at $R=0$ and $R=2$. Although there is no a priori reason why the two minima are equally deep (indeed they are not), that difference is not important for the rough estimate we want to make here. As a simple functional form to represent $E_{\mathrm{i}}^{0}(R)$ we take, again somewhat arbitrarily,

$$
E_{\mathrm{i}}^{0}(R)=E_{\mathrm{i}}^{0}+\frac{k}{\pi^{2}}(1-\cos \pi R)
$$

The factor $1 / \pi^{2}$ has been included so that in the $R \rightarrow 0$ limit

$$
E_{\mathrm{i}}^{0}(R)=E_{\mathrm{i}}^{0}=\frac{1}{2} k R^{2}
$$

The Jahn-Teller relaxation energy $\Delta$ and displacement $R_{\mathrm{JT}}$, defined with reference to (3.2) and (3.4) are

$$
\begin{aligned}
\Delta & =F^{2} / 2 k \\
R_{\mathrm{JT}} & =F / k .
\end{aligned}
$$

The basic reason for choosing expressions of the form (3.1) and (3.3), rather than the lowest order approximations (3.2) and (3.4), is that there is an overall near-symmetry with respect to the situation at $R=0$ and $R=2$. Both positions are minima for the energy and zero for the splittings. We want to represent the physics in a manner which interpolates plausibly between the two positions and which therefore might be reasonable at $R=1$. The importance of $R=1$ is that we have estimates of energy and splittings there. It will also turn out that important values of $R$ will be near enough to $R=1$ that we are beyond the limits of validity of the lowest order approximations.

The additive constant $E_{\mathrm{i}}^{0}$ plays no role and can be dropped. The interstitial energy (2.9) is now

$$
\begin{aligned}
& E_{\mathrm{i}}\left(N_{\mathrm{A}}^{\mathrm{i}}, N_{\mathrm{E}}^{\mathrm{i}}, R\right)=\frac{k}{\pi^{2}}(1-\cos \pi R)+N_{\mathrm{T}}^{\mathrm{i}} \varepsilon_{\mathrm{T}}^{\mathrm{i}}- \\
& -\frac{2 F}{\pi}\left(N_{\mathrm{A}}^{\mathrm{i}}-\frac{1}{2} N_{\mathrm{E}}^{\mathrm{i}}\right) \sin \frac{\pi}{2} R+\frac{1}{2}\left(N_{\mathrm{T}}^{\mathrm{i}}\right)^{2} U^{\mathrm{i}}
\end{aligned}
$$

where

$$
N_{\mathrm{T}}^{\mathrm{i}}=N_{\mathrm{A}}^{\mathrm{i}}+N_{\mathrm{E}}^{\mathrm{i}} .
$$

Let us consider the barrier at $R=1$, i.e., the energy difference between $R=1$ and $R=0$. From (3.6), this is

$$
\begin{aligned}
E_{\mathrm{B}} & =E_{\mathrm{i}}(R=1)-E_{\mathrm{i}}(R=0) \\
& =2 k / \pi^{2}-\frac{2 F}{\pi}\left(N_{\mathrm{A}}^{\mathrm{i}}-\frac{1}{2} N_{\mathrm{E}}^{\mathrm{i}}\right) .
\end{aligned}
$$

We shall use this expression to estimate $k$ from estimates of $E_{\mathrm{B}}$ and of $F$, which we now consider.

The splitting between the $A$ manifold and the $E$ manifold at $R=1$, as given by (2.8) and (3.1) is

$$
\varepsilon_{\mathrm{E}}^{\mathrm{i}}(R=1)-\varepsilon_{\mathrm{A}}^{\mathrm{i}}(R=1)=3 F / \pi .
$$

The Greens function calculation [10] at $R=1$ gave an $\mathrm{E}$ eigenvalue at $1.54 \mathrm{eV}$, and the corresponding $\mathrm{A}$ eigenvalue at $0.32 \mathrm{eV}$. This gives an E-A splitting of $1.22 \mathrm{eV}$ and, correspondingly,

$$
F=1.28 \mathrm{eV} \text {. }
$$

We have no direct way to determine $E_{\mathrm{B}}$, but the following indirect argument provides us with an estimate : careful calculations of the energy barrier for the self-interstitial in silicon along the THT path (corresponding to our path $R=0 \rightarrow R=2$ ) have been carried out by Car et al. [15] and by Bar-Yam and Joannopoulos [16]. Both groups allowed for relaxation of the surrounding atoms and, being primarily interested in the height of the barrier, used well converged basis sets from which reliable values of the energy could be determined. The barrier for the $\mathrm{Si}_{1}^{2+}$ (which, having $N_{\mathrm{A}}=0, N_{\mathrm{E}}=0$, corresponds to $\mathrm{As}_{\mathrm{i}}^{3+}$ ) was calculated as $1.4 \mathrm{eV}$ [15] and $1.2+0.2 \mathrm{eV}$ [16]. A reasonable average of these values is $E_{\mathrm{B}}=1.2 \mathrm{eV}$.

In general, forces in GaAs are about $80 \%$ of what they are in silicon, as judged either by comparing the cohesive energies of the two materials or by comparing their compressibilities. On that basis, we estimate the barrier $E_{\mathrm{B}}$ for $\mathrm{As}_{\mathrm{i}}^{3+}$ at $80 \%$ of the calculated $1.2 \mathrm{eV}$, namely, $E_{\mathrm{B}}=0.96 \mathrm{eV}$. Using (3.7) we obtain

$$
k=4.7 \mathrm{eV}
$$

from which it follows, using 3.9, that

$$
\begin{aligned}
\Delta & =0.17 \mathrm{eV} \\
R_{\mathrm{JT}} & =0.27 .
\end{aligned}
$$

[We must note that the barrier $E_{\mathrm{B}}$ in p-type GaAs has been calculated [10] at $2.5 \mathrm{eV}$. The purpose of that calculation was primarily to obtain levels and incidentally, to establish that $R=1$ is indeed a barrier. The orbital set used in the Greens function 
calculations of reference [10] was too small to give adequate convergence of the total energy, the most sensitive part of the calculation. As a result, the barrier calculated is not of comparable accuracy to those cited for silicon].

We now consider the values of $R$ that minimize the energy (3.6) and the amount by which the energy is lowered. The minimizing value $R_{\mathrm{m}}$ is given by setting $\mathrm{d} E\left(N_{\mathrm{A}}, N_{\mathrm{E}}, R\right) / \mathrm{d} R=0$. Thus, we have the condition

$$
\sin \frac{\pi}{2} R_{\mathrm{m}}=\frac{\pi}{2}\left(N_{\mathrm{A}}^{\mathrm{i}}-\frac{1}{2} N_{\mathrm{E}}^{\mathrm{i}}\right) F / k
$$

The $R$ dependent part of the energy is composed of two terms,

$$
\begin{aligned}
& \varepsilon_{1}(R)=\frac{k}{\pi^{2}}(1-\cos \pi R) \\
& \varepsilon_{2}(R)=\frac{2 F}{\pi}\left(N_{\mathrm{A}}^{\mathrm{i}}-\frac{1}{2} N_{\mathrm{E}}^{\mathrm{i}}\right) \sin \frac{\pi}{2} R
\end{aligned}
$$

whose separate values at $R=R_{\mathrm{m}}$ will be needed :

$$
\begin{aligned}
& \varepsilon_{1}\left(R_{\mathrm{m}}\right)=\left(N_{\mathrm{A}}^{\mathrm{i}}-\frac{1}{2} N_{\mathrm{E}}^{\mathrm{i}}\right)^{2} \Delta \\
& \varepsilon_{2}\left(R_{\mathrm{m}}\right)=2\left(N_{\mathrm{A}}^{\mathrm{i}}-\frac{1}{2} N_{\mathrm{E}}^{\mathrm{i}}\right)^{2} \Delta
\end{aligned}
$$

where

$$
\Delta \equiv F^{2} / 2 k
$$

Thus, the value of the energy (3.6) at its minimum is

$$
\begin{aligned}
E_{1}\left(N_{\mathrm{A}}^{\mathrm{i}}, N_{\mathrm{E}}^{\mathrm{i}}, R_{\min }\right)= & -\left(N_{\mathrm{A}}^{\mathrm{i}}-\frac{1}{2} N_{\mathrm{E}}^{\mathrm{i}}\right)^{2} \Delta+ \\
& +N_{\mathrm{T}}^{\mathrm{i}} \varepsilon_{\mathrm{T}}^{\mathrm{i}}-\frac{1}{2}\left(N_{\mathrm{T}}^{\mathrm{i}}\right)^{2} U^{\mathrm{i}} .
\end{aligned}
$$

The first term here is the Jahn-Teller relaxation

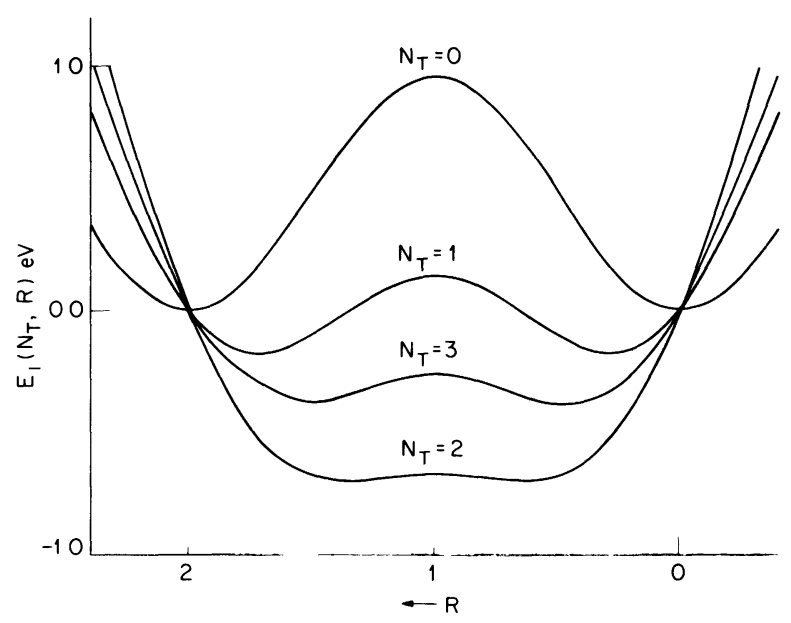

Fig. 2. - The $R$-dependent part of the interstitial energy depends on $N_{\mathrm{T}}$ the occupancy of the Jahn-Teller distorted gap state of nominal $T_{2}$ symmetry. The barrier both lowers and narrows as the first two electrons are added, but this trend reverses for $N_{\mathrm{T}}>2$. energy, caused by occupying states in a degenerate manifold and allowing the system to relax so as to remove that degeneracy. The amount of that relaxation is characterized by $\Delta$.

In figure 2, we plot $\varepsilon(R)=\varepsilon_{1}(R)-\varepsilon_{2}(R)$ for various charge states of $A s_{i}$ using the parameters $F=1.28 \mathrm{eV}$ and $k=4.7 \mathrm{eV}$. In the remaining parts of the paper, we shall carry through the results of using (3.6) with these parameters. We shall illustrate by giving numerical values at all steps. This is merely a pedagogical device. It does not mean that we have forgotten the physical approximations that went into (2.11) nor the somewhat arbitrary choices that led to (3.6), nor the experimental and theoretical error bars on the input parameters.

\section{Effect of the Jahn Teller distortions on the level structure of the isolated $\mathrm{As}_{\mathbf{i}}$.}

Lannoo [12] has recently investigated the occupancy level structure of a $\mathrm{T}_{2}$ symmetry defect level, using a Hamiltonian which is the $R \rightarrow 0$ limit of (3.6).

His treatment is a generalization of the one used by Baraff, Kane, and Schluter to demonstrate the negative $U$ of the silicon vacancy [17]. We review a simplified form of Lannoo's argument, based on the use of (3.6) as an energy function.

For each occupancy of the system, there is a value of $R$, namely $R_{\mathrm{m}}$, for which the energy of the system is a minimum, namely $E_{\min }$. Letting $N_{\mathrm{T}}^{\mathrm{i}} \equiv N_{\mathrm{A}}^{\mathrm{i}}+$ $N_{\mathrm{E}}^{\mathrm{i}}$ be the total number of electrons in the $\mathrm{T}_{2}$ manifold, and letting the A manifold fill before the $\mathrm{E}$, we obtain the occupancies and $E_{\min }$ as given by (3.15) and shown in table I.

Table I.

\begin{tabular}{ccccl}
\hline$N_{\mathrm{T}}$ & $N_{\mathrm{A}}$ & $N_{\mathrm{E}}$ & $N_{\mathrm{A}}-\frac{1}{2} N_{\mathrm{E}}$ & \multicolumn{1}{c}{$E_{\min }$} \\
\hline 0 & 0 & 0 & 0 & 0 \\
1 & 1 & 0 & 1 & $\varepsilon_{\mathrm{T}}+\frac{1}{2} U-\Delta$ \\
2 & 2 & 0 & 2 & $2 \varepsilon_{\mathrm{T}}+2 U-4 \Delta$ \\
3 & 2 & 1 & $3 / 2$ & $3 \varepsilon_{\mathrm{T}}+\frac{9}{2} U-9 / 4 \Delta$ \\
4 & 2 & 2 & 1 & $4 \varepsilon_{\mathrm{T}}+8 U-\Delta$ \\
5 & 2 & 3 & $1 / 2$ & $5 \varepsilon_{\mathrm{T}}+\frac{25}{2} U-\frac{1}{4} \Delta$ \\
6 & 2 & 4 & 0 & $6 \varepsilon_{\mathrm{T}}+18 U$ \\
\hline
\end{tabular}

$\varepsilon_{\mathrm{T}} \equiv \varepsilon_{\mathrm{T}}^{\mathrm{i}} \quad U \equiv U^{\mathrm{i}}=0.33 \mathrm{eV} \quad \Delta \equiv F^{2} / 2 k=0.17 \mathrm{eV}$.

The levels are defined as the differences in adjacent minimum energies. That is, $\varepsilon\left(N_{\mathrm{T}}, N_{\mathrm{T}}-1\right) \equiv$ 
$E_{\min }\left(N_{\mathrm{T}}\right)-E_{\min }\left(N_{\mathrm{T}}-1\right)$. Using table I and the chosen parameters, we obtain

$\varepsilon(1,0)=\varepsilon_{1}-\Delta=\varepsilon_{1}-0.17 \mathrm{eV}$

$\varepsilon(2,1)=\varepsilon_{1}+U-3 \Delta=\varepsilon_{1}-0.18 \mathrm{eV}$

$\varepsilon(3,2)=\varepsilon_{1}+2 U+\frac{7 \Delta}{4}=\varepsilon_{1}+0.96$

$\varepsilon(4,3)=\varepsilon_{1}+3 U+\frac{5 \Delta}{4}=\varepsilon_{1}+1.20 \mathrm{eV}$

$\varepsilon(5,4)=\varepsilon_{1}+4 U+3 \Delta / 4=\varepsilon_{1}+1.45 \mathrm{eV}$

$\varepsilon(6,5)=\varepsilon_{1}+5 U+\Delta / 4=\varepsilon_{1}+1.69 \mathrm{eV}$

where

$$
\varepsilon_{1} \equiv \varepsilon_{\mathrm{T}}^{\mathrm{i}}+\frac{1}{2} U^{\mathrm{i}}
$$

If $\Delta>U / 2$, then $\varepsilon(2,1)$ lies below $\varepsilon(1,0)$ and instead of two separate levels, there is a two electron occupancy level [17] at the average value

$$
\begin{aligned}
\varepsilon(2,0)=\frac{1}{2} & {[\varepsilon(2,1)+\varepsilon(1,0)]=} \\
& =\varepsilon_{1}+\frac{1}{2} U-2 \Delta=\varepsilon_{1}-0.18 \mathrm{eV} .
\end{aligned}
$$

The feature that Lannoo has stressed is the large range of Fermi energy $E_{\mathrm{F}}$ over which $N_{\mathrm{T}}=2$ is the stable situation. If $\Delta<U / 2$, this range is $\varepsilon(2,1)<E_{\mathrm{F}}<\varepsilon(3,2)$, a range of $U+19 \Delta / 4$. If $\Delta>U / 2$, this range is $\varepsilon(2,0)<E_{\mathrm{F}}<\varepsilon(3,2)$, a range of $3 U / 2+15 \Delta / 4$. In either case, this is appreciably larger than $U$, the range of $E_{\mathrm{F}}$ we would have found had we neglected the Jahn Teller relaxation.

The parameters just barely do give a «negative effective $U$ » situation, with $\varepsilon(1,0)-\varepsilon(2,1)=$ $0.001 \mathrm{eV}$. We plot the resulting occupancy levels in figure $3 \mathrm{a}$, placing them seemingly arbitrarily with respect to the band gap of $1.52 \mathrm{eV}$. The actual placement is determined by the parameter $\varepsilon_{\mathrm{T}}^{\mathrm{i}}$, which is free at the moment. In the drawing however, we have already anticipated results of fitting $\varepsilon_{\mathrm{T}}^{i}$ to experiment.

The occupancy levels have meaning only in a situation where the defects can exchange electrons between themselves and an external reservoir at Fermi energy $E_{\mathrm{F}}$. A different description is appropriate when an optical transition ionizes or repopulates a single defect. Such transfers are represented on a configuration coordinate diagram as vertical transitions. They occur at the fixed value of $R$ appropriate to the equilibrium of the initial state.

We obtain these optical transition energies by evaluating (3.6) for both the final and initial states with $R=R_{\mathrm{m}}$ (initial) and taking the differences in the energies. In such case, $\varepsilon_{1}(R)$ is constant and $\varepsilon_{2}(R)$ changes only because of the change in occu-

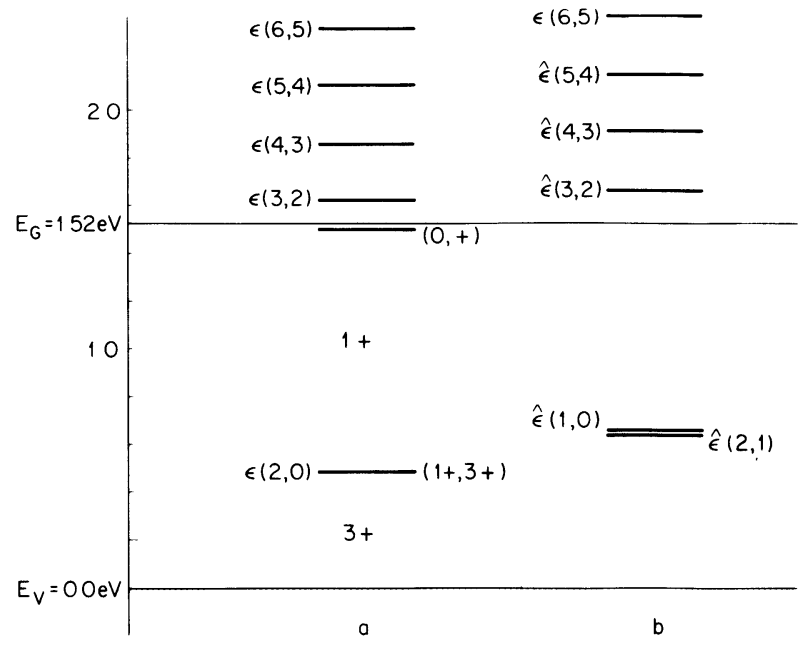

Fig. 3. - a) Occupancy levels for the isolated $A s_{i}$. The stable charge states above and below each level are indicated. The level $\varepsilon(N, M)$ is labelled by the number of electrons in the gap state when the Fermi energy $E_{\mathrm{F}}$ is above $(N)$ or below $(M)$ the level. b) Optical levels for the isolated $\mathrm{As}_{\mathrm{i}} . \hat{\varepsilon}(N, N-1)$ is the minimum value of $h \nu$ needed to add the $N$ th electron to the level from the valence band when the level already contains $N-1$ electrons.

pancy. For transitions in which we excite electrons from the valence band to the defect we get

$\hat{\varepsilon}(1,0)=\varepsilon_{1}=\varepsilon_{1}$

$\hat{\varepsilon}(2,1)=\varepsilon_{1}+U-2 \Delta=\varepsilon_{1}-0.01 \mathrm{eV}$

$\hat{\varepsilon}(3,2)=\varepsilon_{1}+2 U+2 \Delta=\varepsilon_{1}+1.00 \mathrm{eV}$

$\hat{\varepsilon}(4,3)=\varepsilon_{1}+3 U+3 \Delta / 2=\varepsilon_{1}+1.25 \mathrm{eV}$

$\hat{\varepsilon}(5,4)=\varepsilon_{1}+4 U+\Delta=\varepsilon_{1}+1.49 \mathrm{eV}$

$\hat{\varepsilon}(6,5)=\varepsilon_{1}+5 U+\Delta / 2=\varepsilon_{1}+1.74 \mathrm{eV}$

where again, $\varepsilon_{1}=\varepsilon_{\mathrm{T}}^{\mathrm{i}}+\frac{1}{2} U^{\mathrm{i}}$. Each of the vertical transition lies above the corresponding occupancy level because relaxation of the final state energy has not yet occurred.

In the negative effective $U$ situation where $\Delta>U / 2$, the vertical transition $\hat{\varepsilon}(2,1)$ lies below the vertical transition $\hat{\varepsilon}(1,0)$. Light with $h \nu>$ $\hat{\varepsilon}(1,0)$ is thus able to fill both the $(1,0)$ level and the $(2,1)$ levels with electrons raised from the valence band to the defect. In a situation where $\varepsilon(2,0)>0$, the charge of $A s_{i}$ in p-type material is $3+$. Light with $h \nu<\hat{\varepsilon}(1,0)$ does not alter this. However, if $h \nu>\hat{\varepsilon}(1,0)$, then a population of $\mathrm{As}_{\mathrm{i}}$ with charge $2+$ builds up, followed by a population of $\mathrm{As}_{\mathrm{i}}$ with charge $1+$ if the light is strong enough compared to the lifetime of the states. We plot the optical levels in figure $3 \mathrm{~b}$, placing them correctly with respect to the occupancy levels.

Ionization energies, in which an electron is taken 
from the defect to the conduction band, can be calculated in the same way. Again, the energy is evaluated at $R=R_{\mathrm{m}}$ (initial). The energy $E_{\mathrm{G}}$ of the ionized electron at the bottom of the conduction band must be included in the final state energy. It turns out that if $\Delta>U / 2$, then photons with sufficient energy to ionize the $N_{\mathrm{A}}^{\mathrm{i}}=2$ state will also have sufficient energy to ionize the $N_{\mathrm{A}}^{\mathrm{i}}=1$ state.

\section{Levels and excitation energies of the interacting pair.}

Let us consider the energy expression (2.11), using (3.6) for the interstitial energy :

$$
\begin{aligned}
E\left(N_{\mathrm{A}}^{\mathrm{a}},\right. & \left.N_{\mathrm{T}}^{\mathrm{a}}, N_{\mathrm{A}}^{\mathrm{i}}, \mathrm{N}_{\mathrm{E}}^{\mathrm{i}}, R\right)=\frac{k}{\pi^{2}}(1-\cos \pi R) \\
& +N_{\mathrm{A}}^{\mathrm{a}} \varepsilon_{\mathrm{A}}^{\mathrm{a}}+N_{\mathrm{T}}^{\mathrm{a}} \varepsilon_{\mathrm{T}}^{\mathrm{a}}+\frac{1}{2}\left(N_{\mathrm{A}}^{\mathrm{a}}+N_{\mathrm{T}}^{\mathrm{a}}\right)^{2} U^{\mathrm{a}} \\
& -\frac{2 F}{\pi}\left(N_{\mathrm{A}}^{\mathrm{i}}-\frac{1}{2} N_{\mathrm{E}}^{\mathrm{i}}\right) \sin \frac{\pi R}{2}+N_{\mathrm{T}}^{\mathrm{i}} \varepsilon_{\mathrm{T}}^{\mathrm{i}} \\
+ & \frac{1}{2}\left(N_{\mathrm{T}}^{\mathrm{i}}\right)^{2} U^{\mathrm{i}}+Q_{\mathrm{a}} Q_{\mathrm{i}} /[\varepsilon(4-R) b / 2]
\end{aligned}
$$

where

$$
\begin{aligned}
& N_{\mathrm{T}}^{\mathrm{i}}=N_{\mathrm{A}}^{\mathrm{i}}+N_{\mathrm{E}}^{\mathrm{i}} \\
& Q_{\mathrm{a}}=2-N_{\mathrm{A}}^{\mathrm{a}}-N_{\mathrm{T}}^{\mathrm{a}} \\
& Q_{\mathrm{i}}=3-N_{\mathrm{T}}^{\mathrm{i}} .
\end{aligned}
$$

Occupancy levels and vertical transition energies are evaluated just as they were in the last section : for occupancy levels, we take the differences between relaxed energies; for vertical energies, we take the differences between energies evaluated at $R=R_{\mathrm{m}}$ (initial). The interaction term can, in principle, affect the value of $R_{\mathrm{m}}$ (initial). This effect is small enough to ignore, as we can see by linearizing the interaction term so as to obtain a corresponding force constant :

$$
\frac{Q_{\mathrm{a}} Q_{\mathrm{i}}}{\varepsilon(4-R) b / 2}=\frac{Q_{\mathrm{a}} Q_{\mathrm{i}}}{2 \varepsilon b}+Q_{\mathrm{a}} Q_{\mathrm{i}} f R
$$

where

$$
f=\frac{1}{8 \varepsilon b}=0.06 \mathrm{eV}
$$

This is so small compared with the main force constant $F=1.28 \mathrm{eV}$ that we can safely ignore it. We do so, replacing the interaction term in (5.1) by $Q_{\mathrm{a}} Q_{\mathrm{i}} / 2 \varepsilon b$.

Rather than enumerating all the possible occupancies and energies, we shall focus on some of the interesting energy differences in (5.1).

5.1 TRANSITIONS IN WHICH AN ELECTRON IS ADDED TO THE ANTISITE. - The energy differences associated with adding successive electrons to the $\mathrm{As}_{\mathrm{Ga}}$ are as follows :

$$
\begin{gathered}
N_{\mathrm{T}}^{\mathrm{a}}=0, \quad N_{\mathrm{A}}^{\mathrm{a}}=0 \rightarrow 1 \\
\varepsilon_{\mathrm{a}}(1,0)=\varepsilon_{1}^{\mathrm{a}}-Q_{\mathrm{i}} / 2 \varepsilon b \\
\begin{array}{c}
N_{\mathrm{T}}^{\mathrm{a}}=0, \quad N_{\mathrm{A}}^{\mathrm{a}}=1 \rightarrow 2 \\
\varepsilon_{\mathrm{a}}(2,1)=\varepsilon_{1}^{\mathrm{a}}+U^{\mathrm{a}}-Q_{\mathrm{i}} / 2 \varepsilon b \quad(5.2 \mathrm{~b})
\end{array} \\
\begin{array}{r}
N_{\mathrm{A}}^{\mathrm{a}}=2, \quad N_{\mathrm{T}}^{\mathrm{a}}=0 \rightarrow 1 \\
\varepsilon_{\mathrm{a}}(3,2)=\varepsilon_{1}^{\mathrm{a}}+\left(\varepsilon_{\mathrm{T}}^{\mathrm{a}}-\varepsilon_{\mathrm{A}}^{\mathrm{a}}\right)+2 U^{\mathrm{a}}-Q_{\mathrm{i}} / 2 \varepsilon b
\end{array} \\
\text { where } \quad \varepsilon_{1}^{\mathrm{a}}=\varepsilon_{\mathrm{A}}^{\mathrm{a}}+\frac{1}{2} U^{\mathrm{a}}
\end{gathered}
$$

These are the levels of the isolated $\mathrm{As}_{\mathrm{Ga}}$, all shifted by the Coulomb potential $-Q_{\mathrm{i}} / 2 \varepsilon b$ of the nearby interstitial.

5.2. INTERNAL EXCITATION AT THE $\mathrm{As}_{\mathrm{Ga}} \cdot$ - There are two transitions possible. In one, $N_{\mathrm{A}}^{\mathrm{a}}=1 \rightarrow 0$, $N_{\mathrm{T}}^{\mathrm{a}}=0 \rightarrow 1$. In the other, $N_{\mathrm{A}}^{\mathrm{a}}=2 \rightarrow 1, N_{\mathrm{T}}^{\mathrm{a}}=0 \rightarrow 1$. The energy for both of these in this model is the same, namely $\varepsilon_{\mathrm{T}}-\varepsilon_{\mathrm{A}}$, independent of the charge of the nearby $A s_{i}$. This is the $A_{1}-T_{2}$ optical transition of the antisite.

\subsection{TRANSITIONS IN WHICH AN ELECTRON IS ADDED} TO THE INTERSTITIAL. - Both the occupancy levels $\varepsilon(N, N-1)$ and the optical energies $\hat{\varepsilon}(N, N-1)$ to raise an electron from the valence band to the interstitial are the same as those given in section 4 except that they are shifted by $-Q_{\mathrm{a}} / 2 \varepsilon b$, the Coulomb potential of the nearly $\mathrm{As}_{\mathrm{Ga}}$.

5.4 INTERNAL EXCITATIONS AT THE $\mathrm{As}_{\mathrm{i}}$. - The part of (5.1) that changes in such case is $-\frac{2 F}{\pi}\left(N_{\mathrm{A}}^{\mathrm{i}}-\frac{1}{2} N_{\mathrm{E}}^{\mathrm{i}}\right) \sin \frac{\pi R}{2}$. In such a transition, $\Delta N_{\mathrm{A}}^{\mathrm{i}}=-1$ and $\Delta N_{\mathrm{E}}^{\mathrm{i}}=+1$. We evaluate at $R=R_{\mathrm{m}}$ (initial). The resulting energy is

$$
\varepsilon(\mathrm{A} \rightarrow \mathrm{E})=3\left(N_{\mathrm{A}}^{\mathrm{i}}-\frac{1}{2} N_{\mathrm{E}}^{\mathrm{i}}\right)_{\text {initial }} \Delta .
$$

5.5 Charge TRANSFER EXCITATIONS. - The interaction energy $Q_{\mathrm{a}} Q_{\mathrm{i}} / 2 \varepsilon b$ may also change between initial and final situations, contributing to the energy of the excitation.

5.6 LIMIT ON RELEVANT FINAL STATE ENERGIES. The conduction band minimum at $E_{\mathrm{G}}=1.52$ is located at the $\Gamma$ point in the Brillouin zone. The density of states near $\Gamma$ is low. The density of states remains low until an energy of about $0.3 \mathrm{eV}$, where higher lying minima associated with the $L$ and $X$ points contribute heavily [18]. When we evaluate the energy (5.1) with any choice of occupation numbers, we must always ask : what energy would 
be given to a conduction electron if the state were to ionize, undergoing a transition to the ground state containing one less electron ? If the energy is less than $E_{\mathrm{G}}$, the state is stable against ionization. If the energy is between $E_{\mathrm{G}}$ and about $E_{\mathrm{G}}+0.3 \mathrm{eV}$, the state is unstable but is likely to be long lived and potentially important. If the energy is significantly above $E_{\mathrm{G}}+0.3 \mathrm{eV}$ the state will probably be short lived and should probably be ignored.

\section{Comparison with experiment.}

6.1 REVIEW OF EXPERIMENTAL INFORMATION. Such a wealth of information has developed since the review by Martin and Makram-Ebeid [1] that only a few selected aspects can be cited here, many of them already known at the time of the review.

6.1.1 Observed level structure.- EL2 is a donor. The main donor level is at $E_{\mathrm{G}}-0.75 \mathrm{eV}$ but whether it is a single or double level (i.e. whether or not there is one level or two levels close together) has not been definitely established [1]. This last statement really means that « whether the charge state is $1+$ or $2+$ with the main donor level empty is not known ». No levels associated with EL2 have been seen in the upper half gap, that is, above the main donor level $[1,19]$.

In p-type material, a level associated with EL2 has been seen at $E_{v}+0.52 \mathrm{eV}$ [20-22], which is understood to be the capture of the first electron into the empty $A_{1}$ state of the $\mathrm{As}_{\mathrm{Ga}}$.

6.1.2 Photoquenching cross section. - Light, in a band of full width at half maximum (FWHM) of about $0.15 \mathrm{eV}$ centred at $h \nu=1.13 \mathrm{eV}$, drives EL2 from its ground state to its metastable state [23, 24]. Fine structure in this cross section has been observed as a narrow feature at $h \nu=1.04 \mathrm{eV}[25,26]$. Apparently, the sign of this feature depends on experiment conditions. $1.04 \mathrm{eV}$ is also the energy of the nophonon line seen in optical absorption of GaAs samples containing EL2 [27]. The no-phonon line was originally attributed to the $A_{1} \rightarrow T_{2}$ transition at $\mathrm{As}_{\mathrm{Ga}}$, an attribution which has been strengthened by observations of its stress-splitting [28].

6.1.3 Cross section for optical absorption. - Optical absorption specific to EL2 has been measured by observing the absorption of many GaAs samples containing EL2. In each sample, the absorption was measured first with EL2 in its normal state and then again with EL2 in its metastable state [29]. The difference gives the optical absorption of EL2, the sum of the photoquenching cross section plus a smoothly rising background which starts at $h \nu=0.77 \mathrm{eV}$ and is interpreted as the photoionization of the main EL2 donor level. According to Kaminska et al., the peak in the EL2 absorption does not enhance the photocurrent [27] and hence, must be caused by an intracentre transition.

\subsection{INFERENCE FROM THE EXPERIMENTAL INFOR- MATION.}

6.2.1 Connection between EL2 and $\mathrm{As}_{\mathrm{Ga}} \cdot-\mathrm{As}_{\mathrm{Ga}}$ in EL2 was identified by its ESR spectrum, which can be photoinduced in p-type material [30]. When $h \nu<0.52 \mathrm{eV}$, there is no ESR. Between $0.52 \mathrm{eV}<h \nu<0.75 \mathrm{eV}$, the spectrum is seen at full strength because light is able to populate the $\varepsilon_{\mathrm{a}}(1,0)$ level where there is a single electron in the $\mathrm{A}_{1}$ state. At $h \nu>0.75 \mathrm{eV}$, the intensity of the ESR spectrum drops somewhat because light is now able to populate the $\varepsilon_{\mathrm{a}}(2,1)$ level, where two electrons in the $A_{1}$ state pair up to give no net spin. The first connection between EL2 and $\mathrm{As}_{\mathrm{Ga}}$ is that the observed $\varepsilon_{\mathrm{a}}(2,1)$ coincides in energy with the main EL2 donor level as seen by DLTS. The observed $\varepsilon_{\mathrm{a}}(1,0)$ has also recently been seen by DLTS in ptype samples in which EL2 was the dominant defect [20-22].

The reason that light with $h \nu>0.75 \mathrm{eV}$ only weakens, rather than fully destroys, the ESR spectrum is that because $\varepsilon_{\mathrm{a}}(2,1)$ is (accidentally) so close to midgap, light which fills the level can, by ionizing the electron to the conduction band, empty it again. Thus there are always some $\mathrm{As}_{\mathrm{Ga}}$ defects with the $\varepsilon_{\mathrm{a}}(1,0)$ level full and the $\varepsilon_{\mathrm{a}}(2,1)$ level empty to give rise to an ESR signal.

The second connection between $\mathrm{As}_{\mathrm{Ga}}$ and EL2 arises when the light exciting the ESR spectrum has $h \nu \geq 1.1 \mathrm{eV}$, the energy for which the transition to the metable state of EL2 occurs. (After that transition, EL2 remains in the metastable state at low temperatures, even if the light is removed [8].) When $h \nu>1.1 \mathrm{eV}$, the ESR spectrum also disappears. Even if the sample is kept in the dark at low temperatures, light with $0.52 \mathrm{eV}<h \nu<0.75 \mathrm{eV}$ can no longer regenerate the ESR spectrum. The inference is that EL2 in its ground state is $A s_{\mathrm{Ga}}$ : in its metastable state, it is something else which is ESR invisible.

These considerations lead to the conclusion that the levels seen in EL2 are those of $\mathrm{As}_{\mathrm{Ga}}, \varepsilon_{\mathrm{a}}(1,0)$ and $\varepsilon_{\mathrm{a}}(2,1)$, at $0.52 \mathrm{eV}$ and $0.75 \mathrm{eV}$ respectively. Insofar as they are shifted downwards by $Q_{\mathrm{i}} / 2 \varepsilon b$ if the nearby interstitial is charged, that charge must be determined. The argument made in the next subsection settles the matter as far as this model is concerned : the charge must be $Q_{\mathrm{i}}=1+$. Such an assignment is consistent with the conclusion of Bourgoin and Lannoo [6], with the observation by von Bardeleben et al. [4] who report isolated $\mathrm{As}_{\mathrm{Ga}}$ levels higher in the gap than those of EL2, and with the observations of Meyer et al. who found no spin at the $\mathrm{As}_{\mathrm{i}}[11]$. 
6.2.2 Charge of the $\mathrm{As}_{\mathrm{i}} \cdot-$ Note from equation (4.1) or figure 3a that the upper $\varepsilon_{\mathrm{i}}(N, N-1)$ occupancy levels are spaced by $0.24 \mathrm{eV}$. All four of them could be accommodated in the upper half gap, between the main EL2 level $\varepsilon_{\mathrm{a}}(2,1)$ and the conduction band edge. This is a region which, experimentally, contains no levels associated with EL2 [1, 20]. The only placement of the calculated $\mathrm{As}_{\mathrm{i}}$ level structure consistent with this observation is with the $\varepsilon_{\mathrm{i}}(3,2)$ level above $E_{\mathrm{G}}$ and the $\varepsilon_{\mathrm{i}}(2,0)$ level below $\varepsilon_{\mathrm{a}}(2,1)$. [As a matter of fact, $\varepsilon_{\mathrm{i}}(2,0)$ (in the presence of $\left.\mathrm{As}_{\mathrm{Ga}}^{2+}\right)$ must also lie below $\varepsilon_{\mathrm{a}}(1,0)$ [31].] With this level placements, $Q_{\mathrm{i}}=1+$ both in the photo ESR experiments and in the DLTS experiments. Using $\varepsilon=12.85$ [32] and $b=2.45 \AA$ [32] we have

$$
1 / 2 \varepsilon b=0.23 \mathrm{eV} .
$$

The levels of the truly isolated $\mathrm{As}_{\mathrm{Ga}}$ should then be higher than the levels $\varepsilon_{\mathrm{a}}(2,0)=0.75 \mathrm{eV}$ and $\varepsilon_{\mathrm{a}}(1,0)=0.52 \mathrm{eV}$ by about $0.23 \mathrm{eV}$. These levels of the isolated $\mathrm{As}_{\mathrm{Ga}}$ have apparently been seen [4].

6.2.3 Invisibility of the $\mathrm{As}_{\mathrm{i}}$. - The requirement that $\varepsilon_{1}(3,2)$ lies above $E_{\mathrm{G}}$ means that for the Fermi energy in the upper half gap, $Q_{\mathrm{i}}=1+$. The long range $-1 / \varepsilon r$ attractive potential then gives rise to a shallow donor level [33]. The $\varepsilon_{\mathrm{i}}(2,0)$ level, which is located at $3 U / 2+15 \Delta / 4=1.14 \mathrm{eV}$ below $\varepsilon_{\mathrm{i}}(3,2)$, must be in the lower half gap. It might give rise to a DLTS signal in p-type material, but there is no unpaired spin for Fermi energy above or below $\varepsilon_{i}(2,0)$. Even if the DLTS level is observed, there is no ESR spectrum available to connect this level to the interstitial except possibly under photoexcitation. From this point of view, the interstitial would be almost invisible, as Lannoo had suggested [12].

[One way to observe the ESR spectrum of the $\mathrm{As}_{\mathrm{i}}$ might be by photoexcitation in p-type material, using light with $h \nu>\hat{\varepsilon}_{\mathrm{i}}(1,0)$. The problems here would be the same as Watkins encountered in observing the ESR spectrum of the $\mathrm{V}^{+}$silicon vacancy [34] which, like $\mathrm{As}_{\mathrm{i}}^{2+}$, is not stable at any value of $\left.E_{\mathrm{F}}[17].\right]$.

The negative $U$ property that we have calculated here for $A s_{\mathrm{i}}$ is exactly analogous to the negative $U$ property for the Si self interstitial as calculated and discussed by Car et al. [15].

6.2.4 Bounds on the level structure. - There are still two free parameters, $\varepsilon_{\mathrm{A}}^{\mathrm{a}}$, which moves the $\mathrm{As}_{\mathrm{Ga}}$ level structure up and down in the gap, and $\varepsilon_{\mathrm{T}}^{\mathrm{i}}$, which does the same for the $\mathrm{As}_{\mathrm{i}}$ level structure. We shall now determine them as best we can.

The parameter $\varepsilon_{\mathrm{A}}^{\mathrm{a}}$ can be fixed by the knowledge that, in the complex where $Q_{\mathrm{i}}=1+$, the antisite level $\varepsilon_{\mathrm{a}}(2,1)$ lies at $0.75 \mathrm{eV}$. Then, from (5.2bd),

$$
\begin{aligned}
\varepsilon_{\mathrm{A}}^{\mathrm{a}}+\frac{3}{2} U^{\mathrm{a}}-Q_{\mathrm{i}} / 2 \varepsilon b & =0.75 \mathrm{eV} \\
\varepsilon_{\mathrm{A}}^{\mathrm{a}} & =0.64 \mathrm{eV} .
\end{aligned}
$$

Using this value in $(5.2 \mathrm{~cd})$, the energy to capture an electron into the $T_{2}$ state of the $\mathrm{As}_{\mathrm{Ga}}$ in the complex is

$$
\begin{aligned}
\varepsilon^{\mathrm{a}}(3,2)=\varepsilon_{\mathrm{A}}^{\mathrm{a}}+\frac{5}{2} U^{\mathrm{a}} & +\varepsilon_{\mathrm{T}}^{\mathrm{a}}-\varepsilon_{\mathrm{A}}^{\mathrm{a}}- \\
& -Q_{\mathrm{i}} / 2 \varepsilon b=2.03 \mathrm{eV} .
\end{aligned}
$$

This is $0.5 \mathrm{eV}$ above the bottom of the conduction band. Because of the high density of states which sets in at $E_{\mathrm{G}}+0.3 \mathrm{eV}$, the lifetime of the captured electron is likely to be exceedingly short - i.e., the capture will not occur. Note that this important conclusion is almost independent of the model : for an observed initial level at $0.75 \mathrm{eV}$, an observed optical $A_{1} \rightarrow T_{2}$ energy of $1.04 \mathrm{eV}$ and an observed $U^{\mathrm{a}}=0.23 \mathrm{eV}$, the final state level is $0.75+1.04+$ $0.23=2.02 \mathrm{eV}$. The only model assumption here is that $U_{\mathrm{x}}^{\mathrm{a}}=U_{\mathrm{A}}^{\mathrm{a}}$, and this must be true to within a factor of order unity.

The parameter $\varepsilon_{\mathrm{T}}^{\mathrm{i}}$ can not be fixed precisely : we can only place bounds on it. These bounds do depend on the accuracy of the other parameters of the model. The reasoning is as follows : the model gives a spacing between $\varepsilon_{\mathrm{i}}(3,2)$ and $\varepsilon_{\mathrm{i}}(2,0)$ of $3 U / 2+15 \Delta / 4=1.14 \mathrm{eV}$. Since $\varepsilon_{1}(3,2)$ has to be above $E_{\mathrm{G}}=1.52 \mathrm{eV}$ to be out of the gap, the level $\varepsilon_{1}(2,0)$ must lie above $0.38 \mathrm{eV}$. On the other hand, $\varepsilon_{\mathrm{i}}(2,0)$ must lie below the main EL2 midgap level at $0.75 \mathrm{eV}$ since it does not appear in the upper half gap. Thus we have the limits

$$
0.3 \dot{8} \mathrm{eV}<\varepsilon_{\mathrm{i}}(2,0)<0.75 \mathrm{eV}
$$

or, since $\varepsilon_{\mathrm{i}}(2,0)=\varepsilon_{\mathrm{T}}^{\mathrm{i}}+U^{\mathrm{i}}-2 \Delta=\varepsilon_{\mathrm{T}}^{\mathrm{i}}-0.01 \mathrm{eV}$, we get essentially the same bound on $\varepsilon_{\mathrm{T}}^{\mathrm{i}}$ itself

$$
0.37<\varepsilon_{\mathrm{T}}^{\mathrm{i}}<0.74 \mathrm{eV} .
$$

6.2.5 Origin of the main optical absorption of EL2. - The optical absorption peak of EL2 has half width of $0.15 \mathrm{eV}$ and is centred at $h \nu=1.18 \mathrm{eV}$. Below it, at $1.04 \mathrm{eV}$, is a no phonon line whose associated phonons have an energy $\hbar \omega=11 \mathrm{meV}$. The no-phonon line belongs to the $A_{1} \rightarrow T_{2}$ transition at the $\mathrm{As}_{\mathrm{Ga}}[27,28]$. It was originally assumed that the peak at $1.18 \mathrm{eV}$ was the associated vertical transition, which would imply a Franck-Condon relaxation $d_{\mathrm{FC}}$ of $0.14 \mathrm{eV}$. However, the parameters $d_{\mathrm{FC}}=0.14 \mathrm{eV}, \quad \hbar \omega=11 \mathrm{eV}[27]$ imply a Huang 
Rhys factor $S \equiv d_{\mathrm{FC}} / \hbar \omega=13$. In such case, the nophonon line, of relative intensity $\mathrm{e}^{-s} \approx 10^{-6}$ would be unobservable. The peak at $1.18 \mathrm{eV}$ cannot be part of the same transition as the no phonon line. Its origin must be sought elsewhere. Within the structure of the model, this suggests the involvement of the interstitial. Its highest occupied occupancy level, $\varepsilon_{\mathrm{i}}(2,0)$, is according to $(6.4 \mathrm{a})$, in the correct energy range to provide the needed electron. Let us pursue this idea :

the main optical absorption at $1.18 \mathrm{eV}$ has a line shape which is more suggestive of an internal transition than of an ionization [27]. Its failure to contribute markedly to the photocurrent [27] is consistent with this interpretation. This means that the final state of the transition must leave the electron at an energy no higher than $E_{\mathrm{G}}+0.3 \mathrm{eV}$, i.e., below the onset of the heavy density of states in the conduction band. The initial level of the transition, $1.18 \mathrm{eV}$ below this, must therefore lie below $E_{\mathrm{G}}+0.3-1.18=E_{\mathrm{G}}-0.88=0.64 \mathrm{eV}$. This is consistent with the range $(6.4 \mathrm{a})$ we found for $\varepsilon_{\mathrm{i}}(2,0)$. We shall assume in this study that $\varepsilon_{\mathrm{i}}(2,0)$ is indeed the initial level for the main optical transition. This allows us to narrow the limits (6.4) somewhat, namely, to

$$
\begin{aligned}
& 0.38 \mathrm{eV}<\varepsilon_{\mathrm{i}}(2,0)<0.64 \mathrm{eV} \\
& 0.37 \mathrm{eV}<\varepsilon_{\mathrm{T}}^{\mathrm{i}}<0.63 \mathrm{eV} .
\end{aligned}
$$

There are two internal excitations which we now consider, both involving the electron in the $\varepsilon_{\mathrm{i}}(2,0)$ level. The first is the internal $A \rightarrow E$ transition of interstitial. The vertical energy of that transition, according to (5.3) is $6 \Delta=1.02 \mathrm{eV}$ which, within an energy uncertainty of $25 \mathrm{meV}$ for $\Delta$, (i.e. $\Delta=0.195 \mathrm{eV}$ instead of $0.17 \mathrm{eV}$ ) is the energy of the vertical transition.

Transitions at the $\mathrm{As}_{\mathrm{i}}^{+}$will be broadened by the zero-point oscillations of $\mathrm{As}_{i}^{+}$about its equilibrium position. The line shape is worked out in the appendix. It depends on the energy of the phonons describing the oscillations about the equilibrium. Their energy, determined from the functional (5.1), using the parameters of this paper and the mass of the arsenic atom, is $7.3 \mathrm{meV}$ (again, see the appendix). The line width is temperature dependent. We find a FWHM of $100 \mathrm{meV}$ at $0 \mathrm{~K}$, of $200 \mathrm{meV}$ at $80 \mathrm{~K}$, and of $340 \mathrm{meV}$ at $170 \mathrm{~K}$. This is to be compared with the observed $150 \mathrm{meV}$ at $80 \mathrm{~K}$.

Another internal transition that we consider is an intra-centre charge transition, in which the initial complex $\mathrm{As}_{\mathrm{Ga}}^{0}-\mathrm{As}_{\mathrm{i}}^{+}$is transformed to $\mathrm{As}_{\mathrm{Ga}}^{-}-\mathrm{As}_{\mathrm{i}}^{2+}$. In terms of occupation numbers, this transition is described by $\left(N_{\mathrm{A}}^{\mathrm{a}}=2, N_{\mathrm{T}}^{\mathrm{a}}=0, N_{\mathrm{A}}^{\mathrm{i}}=2\right.$, $\left.N_{\mathrm{E}}^{\mathrm{i}}=0\right)$ going to $\left(N_{\mathrm{A}}^{\mathrm{a}}=2, \quad N_{\mathrm{T}}^{\mathrm{a}}=1, \quad N_{\mathrm{A}}^{\mathrm{i}}=1\right.$, $N_{\mathrm{E}}^{\mathrm{i}}=0$ ) while $R$ stays fixed at $R=R_{\mathrm{m}}$ (initial). The energy of that transition, evaluated as the differences in the energy functional (5.1), is

$$
\begin{aligned}
E^{*} & \equiv E(2,1,1,0, R)-E(2,0,2,0, R) \\
& =\varepsilon_{\mathrm{T}}^{\mathrm{a}}+\frac{5}{2} U^{\mathrm{a}}-\varepsilon_{\mathrm{T}}^{\mathrm{i}}-\frac{3}{2} U^{\mathrm{i}}+4 \Delta-2 /(2 \varepsilon b) \\
& =1.96 \mathrm{eV}-\varepsilon_{\mathrm{T}}^{\mathrm{i}} .
\end{aligned}
$$

Using (6.5b), we have

$$
1.29 \mathrm{eV}<E^{*}<1.55 \mathrm{eV} \text {. }
$$

The lower limit here is reasonably close to the observed $1.18 \mathrm{eV}$. The vibrational broadening of this line, again using the theory given the appendix, is $2 / 3$ that of the A-E transition. Thus, we have a FWHM of $67 \mathrm{meV}$ at $0 \mathrm{~K}$, of $133 \mathrm{meV}$ at $80 \mathrm{~K}$ and of $227 \mathrm{meV}$ at $170 \mathrm{~K}$, again, reasonably close to the $150 \mathrm{meV}$ at $80 \mathrm{~K}$ that has been observed.

We have no easy way to argue from the observed intensities which of these two transitions is the dominant one. Indeed, they both have features that reduce their intensity below that of a strongly allowed (e.g., $A_{1} \rightarrow T_{2}$ ) optical transition. The weakening factor in the $\mathrm{A} \rightarrow \mathrm{E}$ transition is symmetry : the A level and the $E$ level were partners in a formerly degenerate $T_{2}$ manifold. Light cannot cause transitions between states in a $T_{2}$ manifold. Only if the wave functions have distorted sufficiently because the environment has less than $T_{d}$ symmetry can the transition occur.

The weakening factor in the internal charge transfer transition is wave function overlap : there must be overlap for the transition to occur. The A wave function of the $A s_{i}$ has a lobe pointing towards the $\mathrm{As}_{\mathrm{Ga}}$, which helps the overlap, but the $T_{2}$ wave function of the $\mathrm{As}_{\mathrm{Ga}}$ has lobes along the $\langle 111\rangle$ bonding directions, not along the $\langle 111\rangle$ antibonding direction where the $\mathrm{As}_{\mathrm{i}}$ sits. This hurts the overlap. Clearly a more quantitative calculation would be useful.

Experimentally, however, the complete quenching of the main optical absorption peak when EL2 goes to its metastable state argues for the important transition being charge transfer, not the $\mathrm{A} \rightarrow \mathrm{E}$ transition at the interstitial. The argument here is that all $A s_{i}$, whether part of the complex or free, will exhibit the $\mathrm{A} \rightarrow \mathrm{E}$ transition at the same energy and intensity. The EL2 transition to the metastable state removes only those $\mathrm{As}_{\mathrm{i}}$ which are part of the complex. Thus, complete disappearance of the main optical peak means either that there are no free $A s_{i}$ or that the $\mathrm{A} \rightarrow \mathrm{E}$ transition has negligible strength. Since the $\mathrm{As}_{\mathrm{Ga}}-\mathrm{As}_{\mathrm{i}}$ pair regenerates readily after thermal dissociation, there must be appreciable $A s_{i}$ in the sample. This implies that the $\mathrm{A} \rightarrow \mathrm{E}$ intensity is too weak to be important.

6.2.6 Mechanism for photoquenching EL2. - The earliest mechanism proposed by von Bardeleben $e t$ 
al. $[4,5]$ is basically the following charge transfer mechanism : starting as the $\mathrm{As}_{\mathrm{Ga}}^{0}-\mathrm{As}_{\mathrm{i}}^{+}$complex, the $\mathrm{As}_{\mathrm{Ga}}$ captures an electron which is present because some of the other $\mathrm{As}_{\mathrm{Ga}}$ have been ionized. The complex is then $\mathrm{As}_{\mathrm{Ga}}^{-}-\mathrm{As}_{\mathrm{i}}^{+}$and the resulting Coulomb attraction causes the $\mathrm{As}_{\mathrm{i}}$ to move in closer, initiating a substantial rearrangement of atoms [7]. A charge transfer mechanism has also been suggested by Samuelson and Omling [35].

One difficulty with this proposal in its simplest form is that the $T_{2}$ level of the antisite is located too high to capture, as we saw in section 6.2.4. Another difficulty is that photons of $h \nu>0.77 \mathrm{eV}$ generate electrons in the conduction band (because of the EL2 midgap level which is ionized to the conduction band and refilled from the valence band) while photo quenching does not occur until $h \nu>1.1 \mathrm{eV}$.

Both of these difficulties disappear if the event initiating the metastable transition is the emptying of an electron from the $\mathrm{As}_{\mathrm{i}}(2,0)$ level. After this occurs, the interstitial has charge $2+$. Its added Coulomb potential drops the $T_{2}$ capture level of the $\mathrm{As}_{\mathrm{Ga}}$ from $0.5 \mathrm{eV}$ in the conduction band (Sect. 6.2.4) to $0.5-0.23=0.27 \mathrm{eV}$ in the conduction band. Capture of one of the photoionized electrons is now possible. Then, Coulomb attraction

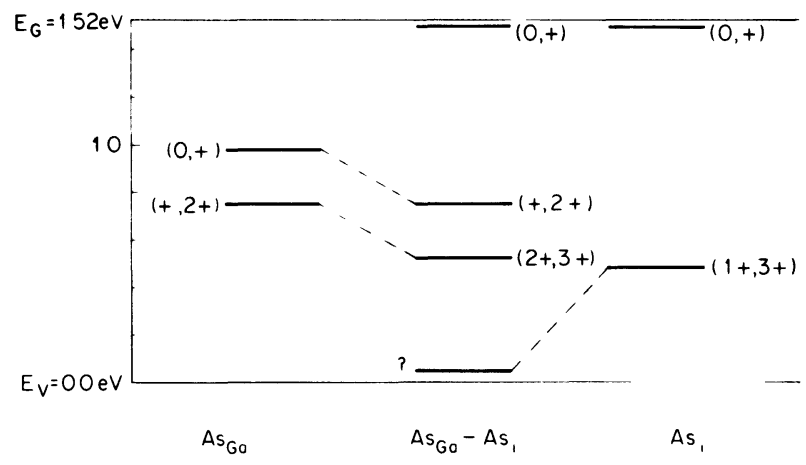

Fig. 4. - Occupancy levels for the isolated $\mathrm{As}_{\mathrm{Ga}}$, for the isolated $A s_{i}$ and for the weakly interacting $A s_{G a}-A s_{i}$ pair.

between the $\mathrm{As}_{\mathrm{Ga}}^{-}$and the $\mathrm{As}_{\mathrm{i}}^{2+}$ can cause the mobile interstitial to cross the low barrier, allowing the proposed rearrangement to occur. Alternatively and even more likely, the same $\left(\mathrm{As}_{\mathrm{Ga}}^{-}-\mathrm{As}_{\mathrm{i}}^{2+}\right)$ state is reached via the internal charge transfer transition. The $R$ dependent part of the energy (5.1a) for the $\left(\mathrm{As}_{\mathrm{Ga}}^{-}-\mathrm{As}_{\mathrm{i}}^{2+}\right)$ complex is shown in figure 5 .

If the $\mathrm{A} \rightarrow \mathrm{E}$ optical transition we discussed as a cause of the main optical absorption is important, and if its final state is in the conduction band (as appears likely) then one of its decay channels is via ionization. It could then initiate the transition to the metastable by the process we have just described. This mechanism, however, would not work in a junction where the electric field sweeps away all the

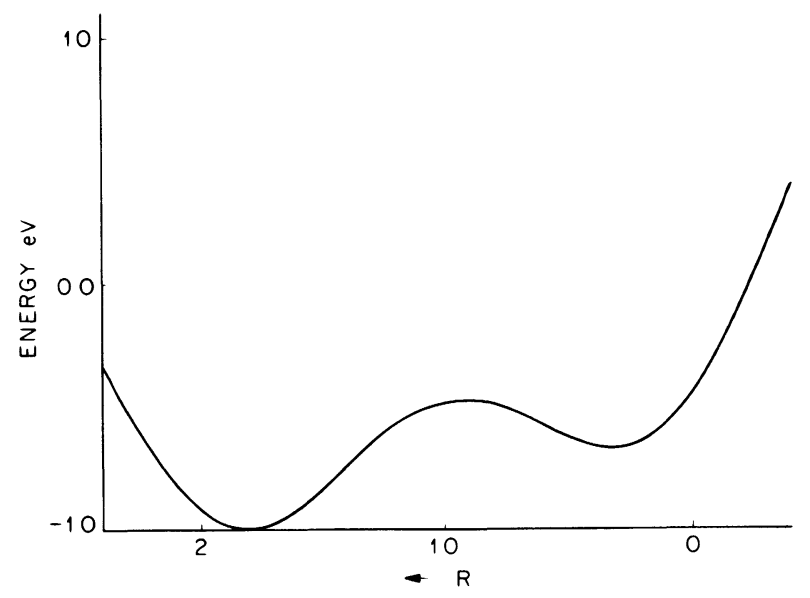

Fig. 5. $-R$ dependent part of the energy in equation (5.1a) for the $\left(\mathrm{As}_{\mathrm{Ga}}^{-}-\mathrm{As}_{\mathrm{i}}^{2+}\right)$ complex resulting from the internal charge transfer excitation.

electrons before they can be captured by the $\mathrm{As}_{\mathrm{Ga}}$. On the other hand, the internal charge transfer mechanism will operate in a junction. It has all the features needed to trigger the transition to the metastable along the lines proposed by von Bardeleben et al. [7].

\section{Summary and conclusions.}

In the proceeding sections, we have devised a simple parametrized model for the total energy of the weakly interacting $A s_{\mathrm{Ga}}-A s_{\mathrm{i}}$ defect pair. Using this model, we deduced the levels and internal excitation energies of the complex. This model describes four of the most prominent experimental features of the EL2 defect, and ascribes them to three different processes available to the $A s_{\mathrm{Ga}}-\mathrm{As}_{\mathrm{i}}$ defect pair. The first feature is the main EL2 donor level at $E_{\mathrm{c}}-0.75 \mathrm{eV}$. This is ascribed to capture or ionization of the second electron in the $A_{1}$ state of the $\mathrm{As}_{\mathrm{Ga}}$. The second feature is the zero phonon line at $h \nu>1.04 \mathrm{eV}$. This is ascribed to the $\mathrm{A}_{1} \rightarrow \mathrm{T}_{2}$ transition at the $\mathrm{As}_{\mathrm{Ga}}$. (Within the simple model, this transition has the same energy with either one or two electrons initially occupying the $A_{1}$ state. This is clearly an over simplication.) The third feature is the main optical absorption peak near $h \nu>1.18 \mathrm{eV}$. This is ascribed to an internal charge transfer excitation in which $\left(\mathrm{As}_{\mathrm{Ga}}^{0}-\mathrm{As}_{\mathrm{i}}^{+}\right) \rightarrow\left(\mathrm{As}_{\mathrm{Ga}}^{-}-\right.$ $\left.\mathrm{As}_{\mathrm{i}}^{2+}\right)$. Although $\mathrm{As}_{\mathrm{Ga}}^{-}$is not stable as an isolated defect, nor even in the vicinity of $\mathrm{As}_{\mathrm{i}}^{+}$, the added Coulomb attraction of the $\mathrm{As}_{\mathrm{i}}^{2+}$ is sufficient to stabilize it. The fourth feature is the EL2 transition to the metastable. This is ascribed to an atomic rearrangement [7] triggered by the extra Coulomb attraction between the defects after they undergo the charge transfer responsible for the main optical absorption. Thus, the shape of the photocapacitance 
transient [8] is understood as reflecting two processes: the rapid rise is caused by the partial emptying of the main EL2 donor level, as the second electron in the $A_{1}$ state of the $\mathrm{As}_{\mathrm{Ga}}$ is ionized and partially refilled from the valence band. The slow decay of the photocapacitance is controlled by the rate of transition to the metastable state, an event initiated by internal transfer of charge. To zeroth order then, the rise is governed by an isotropic process at the $\mathrm{As}_{\mathrm{Ga}}$, while the decay is governed by a process with inherent $\mathrm{C}_{3 \mathrm{~V}}$ symmetry, since both the $A s_{\mathrm{Ga}}$ and the $A s_{\mathrm{i}}$ along the $\langle 111\rangle$ direction are equally involved. These symmetries have recently been confirmed by hydrostatic stress experiments [36].

An important feature of the model is that it allows Jahn-Teller relaxation of the $\mathrm{As}_{\mathrm{i}}$ equilibrium configuration [12]. The amount of that relaxation is characterized by an energy parametrer $\Delta$, about which no experimental information exists. We estimated the size of $\Delta$ by making use of the results of self consistent Greens function calculations which had previously been carried out for other purposes $[10,15,16]$.

Another important energy parameter of the models is $U^{\mathrm{i}}$, the energy spacing between adjacent levels of the interstitial when no Jahn-Teller effect is allowed. Again, there is no experimental information. We estimated the size of $U^{i}$ by self consistent Greens function calculations carried out especially for that purpose [13]. The parameters $\Delta$ and $U^{\mathrm{i}}$ fully determine the spacing between levels of the relaxed $\mathrm{As}_{\mathrm{i}}$. The level structure predicted for the $\mathrm{As}_{\mathrm{i}}$ interstitial is a two electron level (a « negative effective $U$ » situation) in the lower half gap, plus an effectivemass-like donor level below the ordinary donor energy in GaAs. The occupancy of these levels is such that $\mathrm{As}_{\mathrm{i}}$ will have no ESR spectrum except possibly under optical excitation in $\mathrm{p}$ type material.

Let us now consider two other aspects of this work. The first aspect is how sensitive are the conclusions to the parameters of the model. Besides $\Delta$ and $U^{\mathrm{i}}$, the model contains four other parameters, namely, $U^{\text {a }}$ (the spacing between the $A_{1}$ levels of the $\mathrm{As}_{\mathrm{Ga}}$ ), $\varepsilon_{\mathrm{T}}^{\mathrm{a}}-\varepsilon_{\mathrm{A}}^{\mathrm{a}}$ (the optical transition energy at the $\left.A s_{G a}\right), \varepsilon_{T}^{i}$, an energy which moves the calculated level structure of the $\mathrm{As}_{\mathrm{i}}$ relative to the valence and conduction band edges, and $\varepsilon_{\mathrm{A}}^{\mathrm{a}}$, an energy which does the same thing for the $\mathrm{As}_{\mathrm{Ga}}$. The parameters $U^{\mathrm{a}}$ and $\varepsilon_{\mathrm{T}}^{\mathrm{a}}-\varepsilon_{\mathrm{A}}^{\mathrm{a}}$ have been calculated previously using the self consistent Greens function technique [14], and the values obtained are close to those observed [27, 28, 30]. In our model here, wè used the values based on experiment. The level structure of $\mathrm{As}_{\mathrm{Ga}}$ has been calculated by many different groups [13, 14, 37]. There is some spread in the value of $\varepsilon_{\mathrm{A}}^{\mathrm{a}}$ deduced from these calculations. Two of them $[13,37]$ are close to what would be deduced from experiment. In our model here, we used the value based on experiment. The level structure of the isolated $\mathrm{As}_{\mathrm{i}}$ in the absence of Jahn-Teller distortions has been calculated previously using the self consistent Greens function technique [13], with the results presented graphically in reference [13] and numerically in reference [10]. From the numerical result, one can deduce that $\varepsilon_{\mathrm{T}}^{\mathrm{i}}=0.66 \mathrm{eV}$. However, starting from the Jahn-Teller relaxed levels as calculated here, and by relying on the premise of this paper, namely that EL2 (which experimentally has no levels in the upper half gap $[1,20])$ is the weakly interacting pair, one is able to place an (experimental) limit on $\varepsilon_{\mathrm{T}}^{\mathrm{i}}$, namely $0.37 \mathrm{eV}<\varepsilon_{\mathrm{T}}^{\mathrm{i}}<$ $0.74 \mathrm{eV}$. The calculated $E_{\mathrm{T}}^{\mathrm{i}}$ value was in this range.

This really leaves $\Delta$ as the only parameter for which there is no direct experimental information. We must therefore state how our conclusions depend on the size of $\Delta$, which we have estimated at $0.17 \mathrm{eV}$ : first ; our conclusion that the $\mathrm{As}_{\mathrm{i}}$ level spacing is large enough to allow no levels in a half gap of $0.75 \mathrm{eV}$ demands that $\Delta>0.13 \mathrm{eV}$. Second : our conclusion that $\mathrm{As}_{\mathrm{i}}$ has a two-electron occupancy level and thus be invisible to ESR requires that $\Delta>U^{\mathrm{i}} / 2=0.16 \mathrm{eV}$. Even if $\Delta$ is smaller, the range of $E_{\mathrm{F}}$ over which an ESR spectrum would be seen is $U^{\mathrm{i}}-2 \Delta$. This might be so small as to cause the spectrum to be missed. Third: the experimental evidence that there exists a barrier keeping the $\mathrm{As}_{\mathrm{i}}$ close to two bond lengths distance must be considered.

It is not clear from the published account [11] how far the interstitial can be from the $T_{d}$ position and still be consistent with what Meyer et al. observe [11]. If $\Delta>0.21 \mathrm{eV}$, the position $R=1$ becomes an energy minimum, not a barrier, for $\mathrm{As}_{\mathrm{i}}^{+}$. An experimental limitation on the size of $\Delta$ may develop if the Padeborn group is able to show that the $A s_{i}$ is closer than half a bond length from the $T_{d}$ point. The value we estimated for $\Delta$ is consistent with a negative $U$ situation, no levels in the upper half gap, a barrier at $R=1$, and it results, moreover, in a calculated line width for the main optical transition $(133 \mathrm{meV}$ at $80 \mathrm{~K})$ which is very close to the observed $150 \mathrm{meV}$ at $80 \mathrm{~K}$.

The last aspect of this work that we must discuss are the problems inherent in the premise itself that EL2 is the interacting pair. The first of these is : what is the source of the binding energy that keeps the $\mathrm{As}_{\mathrm{i}}$ near the As? The probable charge state $\mathrm{As}_{\mathrm{Ga}}^{0}-\mathrm{As}_{\mathrm{i}}^{+}$rules out long range Coulomb attraction. The calculation of Bachelet and Scheffler [37] makes it unlikely that $\mathrm{As}_{\mathrm{Ga}}$ is the source of any strain field which could interact with the strain field of the Jahn-Teller distorted $\mathrm{As}_{\mathrm{i}}$. We have (unpublished) made a preliminary estimate that the short range 
attraction between a charged $A s_{i}$ and a neutral but polarizable $\mathrm{As}_{\mathrm{Ga}}$ leads to binding of about $50 \mathrm{meV}$ but this estimate needs to be verified by a more complete calculation.

A second problem in the premise that EL2 is the interacting pair is that of the nature of the atomic configuration of the EL2 metastable. If that rearrangement is by severe rebonding as von Bardeleben et al. have suggested [7], the energetics of that rebonding must be weak enough to allow the metastable to ground state recovery barrier to be observed $0.34 \mathrm{eV}[1]$.

This paper has not dealt with these problems of the inherent stability of the pair, the nature of the metastable, nor the nature of the recovery from the metastable. It has dealt only with the properties of the weakly interacting pair. It has found nothing to contradict, and much to support, the proposal that the weakly interacting $\mathrm{As}_{\mathrm{Ga}}-\mathrm{As}_{\mathrm{i}}$ pair and EL2 in its ground state are, in fact, one and the same.

\section{Appendix.}

OPTICAL LINESHAPE. - Let us consider the configuration coordinate diagram of figure 6 , where the two energy curves $E_{\mathrm{g}}(Q)$ (ground state) and $E_{\mathrm{e}}(Q)$ do not necessarily have a parabolic shape. We

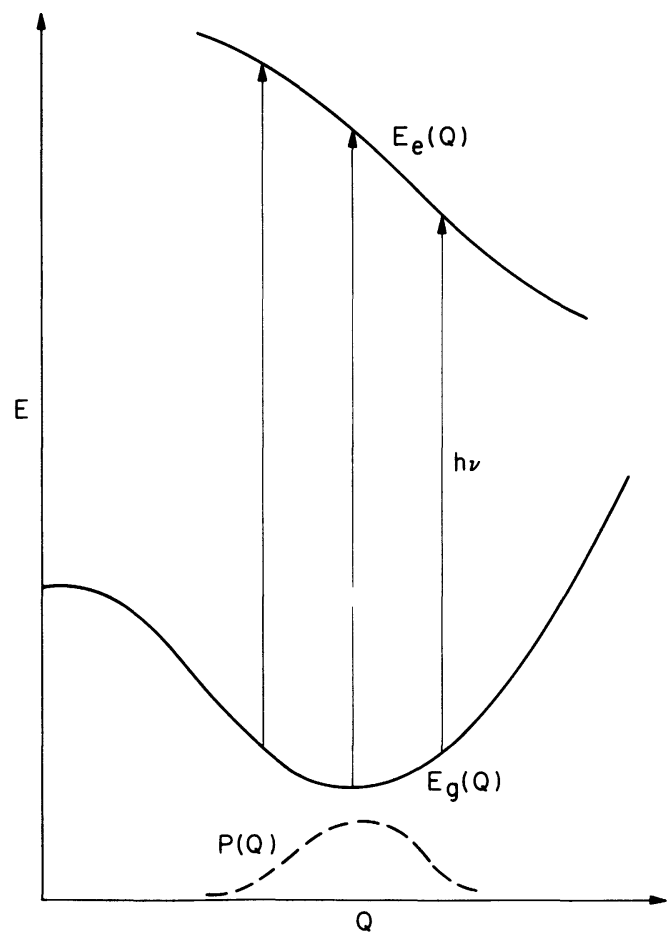

Fig. 6. - Origin of the optical line shape broadening in the strong coupling limit. The total energy of the system in its ground state is $E_{\mathrm{g}}(Q)$ and it can undergo a vertical transition to a final state energy $E_{\mathrm{e}}(Q)$. The range of $Q$ values over which this occurs is determined by the Gaussian spread of the vibronic wave function in the ground state, and the temperature. evaluate the line shape function in the strong coupling limit where one can assume that optical transitions are vertical, i.e. occur at fixed $Q$. The relation between the frequency $\nu$ of the absorbed light and $Q$ can thus be written

$$
h \nu=E_{\mathrm{c}}(Q)-E_{\mathrm{g}}(Q) .
$$

Calling $P(Q) \mathrm{d} Q$ the probability of finding the system in the interval $\mathrm{d} Q$ around $Q$ we get the optical line shape function $G(h \nu)$ through the relation

$$
G(h \nu) \mathrm{d} h \nu=P(Q) \mathrm{d} Q .
$$

$P(Q)$ can be calculated easily by using the harmonic approximation near the minimum of $E_{\mathrm{g}}(Q)$. At temperature $T$ one gets [38]

$$
\begin{aligned}
P(Q)= & \left(\frac{M \omega_{\mathrm{g}}}{\pi \hbar \operatorname{coth}\left(\frac{\hbar \omega_{\mathrm{g}}}{2 k T}\right)}\right)^{1 / 2} \times \\
& \times \exp -\left(\frac{M \omega_{\mathrm{g}} Q^{2}}{\hbar \operatorname{coth}\left(\frac{\hbar \omega_{\mathrm{g}}}{2 k T}\right)}\right)
\end{aligned}
$$

where $\omega_{\mathrm{g}}$ is the phonon frequency in the ground state and $M$ the mass of mode $Q$. An easy evaluation of $G(h \nu)$ is obtained by linearizing equation (A.1) in the interval of interest near $Q=0$. This leads to

$$
h \nu=h \bar{\nu}+F_{\mathrm{e}} Q
$$

with

$$
F_{\mathrm{e}}=\left(\frac{\partial E_{\mathrm{e}}}{\partial Q}\right)_{Q=0}
$$

From equation (A.2 to 4) one then gets for the lineshape function

$$
G(h \nu)=\frac{1}{\sqrt{2 \pi \mu_{2}}} \exp -\frac{(h \nu-h \bar{\nu})^{2}}{2 \mu_{2}}
$$

with $\mu_{2}$ defined by

$$
\mu_{2}=\frac{\hbar F_{\mathrm{e}}^{2}}{2 M \omega_{\mathrm{g}}} \operatorname{coth}\left(\frac{\hbar \omega_{\mathrm{g}}}{2 k T}\right) .
$$

This is the usual Gaussian lineshape but extended to a more general situation. The half width of this curve at half maximum, HWHM, is given by

$$
\Delta h \nu=1.2 \sqrt{\mu_{2}}
$$

and the FWHM $=2 \Delta h \nu$.

We now want to apply this lineshape theory to the $\mathrm{A} \rightarrow \mathrm{E}$ internal transition of the $\mathrm{As}_{\mathrm{i}}^{+}$. For this we 
start from the general expression for the energy (Eq. (3.6))

$E=\frac{k}{\pi^{2}}(1-\cos \pi R)-\left(N_{\mathrm{A}}-\frac{N_{\mathrm{E}}}{2}\right) \frac{2 F}{\pi} \sin \frac{\pi}{2} R$.

The ground state $E_{\mathrm{g}}$ corresponds to $N_{\mathrm{A}}=2$, $N_{\mathrm{E}}=0$ and the excited state to $N_{\mathrm{A}}=1 N_{\mathrm{E}}=1$. The numerical values are $F=1.28 \mathrm{eV} \mathrm{k}=4.7 \mathrm{eV}$. The minimum in the ground state occurs for

$$
\sin \frac{\pi}{2} R_{\mathrm{g}}=\frac{F \pi}{k} .
$$

From this it is easy to evaluate the following quantities

$$
F_{\mathrm{e}}=\frac{2}{b}\left(\frac{\partial E_{\mathrm{e}}}{\partial R}\right)_{R_{\mathrm{g}}}=0.8 \mathrm{eV} / \AA
$$

and the effective force constant

$$
k_{\mathrm{g}}^{*}=\left(\frac{2}{b}\right)^{2}\left(\frac{\partial^{2} E_{\mathrm{g}}}{\partial R^{2}}\right)_{R \mathrm{~g}}=1.26 \mathrm{eV} /(\AA)^{2} .
$$

From the knowledge of $k^{*}$ one can evaluate the phonon energy $\hbar \omega_{\mathrm{g}}=\hbar \sqrt{k_{\mathrm{g}}^{*} / M}$ where we take $M$ to be the mass of the arsenic atom. This gives

$$
\hbar \omega_{\mathrm{g}}=7.3 \mathrm{meV} .
$$

From these numbers it is now a simple matter to determine the half width $\Delta \mathrm{h} \nu$ at different temperatures, using equation $($ A.7, 8). We get the following results

$$
\begin{aligned}
(\Delta h \nu)_{T=0 \mathrm{~K}} & \sim 50 \mathrm{meV} \\
(\Delta h \nu)_{T=80 \mathrm{~K}} & \sim 100 \mathrm{meV} \\
(\Delta h \nu)_{T=170 \mathrm{~K}} & \sim 140 \mathrm{meV} .
\end{aligned}
$$

These values and their temperature dependence compare very well with experiment.

It is interesting to notice that, with our numbers, the barrier between the minimum at $R_{\mathrm{g}}$ and the saddle-point at $R=1$ is very small $(20 \mathrm{meV})$ i.e. of the order of $3 \hbar \omega_{\mathrm{g}}$. Thus our estimation will only hold true at low temperature $T \leq \frac{3}{2} \hbar \omega_{\mathrm{g}}$ i.e. up to $120 \mathrm{~K}$ which is enough for our purpose. A final point is that one can refine the lineshape theory by incorporating terms in $Q^{2}$ in (A.4). This leads to an asymmetry in the lineshape which we found to be small (less than $10 \%$ ) in agreement with experiment.

\section{References}

[1] Martin, G. M. and Makram-Ebeid, S., in Deep Centers in Semiconductors edited by S. T. Pantelides (Gordon and Breach, New York) 1985 , p. 399.

[2] von BARdeleben, H. J. and Bourgoin, J. C., in Proceedings of the Fifth International «Lund » Conference on Deep Level Impurities in Semiconductors, St. Andrews, Scotland, June 1985 (unpublished).

[3] von Bardeleben, H. J., Stievenard, D., BourGoIn, J. C. and Huber, A., Appl. Phys. Lett. 47 (1985) 970.

[4] von Bardeleben, H. J., Stievenard, D., DeresMes, D., Huber, A. and Bourgoin, J. C., Phys. Rev. B 34 (1986) 7192.

[5] Stievenard, D., Von Bardeleben, H. J., BourGoIN, J. C. and HubER, A., in Proceedings of the Fourteenth International Conference on Defects in Semiconductors, Paris, 1986, edited by H. J. von Bardeleben (Transtech, Switzerland) p. 305.

[6] Bourgoin, J. C. and Lannoo, M. (this volume).

[7] von BARDEleben, H. J., Bourgoin, J. C., STIEVENARD, D. and LANNOO, M. (to be published).

[8] Vincent, G. and Bois, D., Solid State Commun. 27 (1978) 431.
[9] Spaeth, J.-M., in Proceedings of the Fourth International Conference on Semi-Insulating III-V Materials, Hakone, Japan, 1986 (to be published).

[10] Baraff, G. A. and Schluter, M., Phys. Rev. B 35 (1987) 6154.

[11] Meyer, B. K., HofmanN, D. M. and Spaeth, J.M., in Proceedings of the Fourteenth International Conference on Defects in Semiconductors, Paris, 1986, edited by H. J. von Bardeleben (Transtech, Switzerland), p. 311.

[12] LANNOO, M. (to be published).

[13] Baraff, G. A. and Schluter, M., Phys. Rev. Lett. 55 (1985) 1327.

[14] BAChelet, G., Schluter, M. and BarafF, G. A., Phys. Rev. B 27 (1983) 2545.

[15] Car, R., Kelley, P. J., Oshiyama, A. and PanTElides, S. T., Phys. Rev. Lett. 52 (1984) 1814.

[16] Bar-Yam, Y. and Joannopoulos, J., Phys. Rev. B 30 (1984) 1844.

[17] BARAFF, G. A., KANE, E. O. and Schluter, M., Phys. Rev. Lett. 43 (1979) 956, Phys. Rev. B 21 (1980) 5662.

[18] Aspnes, D. E., Olson, C. G. and LYNCH, D. W., Phys. Rev. Lett. 37 (1976) 766.

[19] Lagowski, J., Matsui, M., KanG, C. H., Gatos, H. C., Meyer, B. K. and SPAeth, J.-M., private communication. 
[20] Lagowski, J., Lin, D. G., Chen, T.-P., SkowRonski, M. and Gatos, H. C., Appl. Phys. Lett. 47 (1985) 929.

[21] Wosinski, T., Appl. Phys. A 36 (1985) 213.

[22] OsaKa, J., Окамото, Н. and Kobayashi, K., in Proceedings of the IV International Conference on Semi-Insulating III-V Materials, Hakone Japan 1986.

[23] Vincent, G., Bois, D. and Chantre, A., J. Appl. Phys. 53 (1982) 3643.

[24] Dischler, B., Fuchs, F. and Kaufman, U., Appl. Phys. Lett. 48 (1986) 1282.

[25] Skowronski, M., Lagowski, J. and Gatos, H. C., Phys. Rev. B 32 (1985) 4264.

[26] Tsukuda, N., Kikuta, T. and Ishida, K., Phys. Rev. B 33 (1986) 8859 .

[27] Kaminska, M., Skowronski, M., LAgowski, J., Parsey, J. M. and Gatos, H. C., Appl. Phys. Lett. 43 (1983) 302.

[28] KaminsKa, M., Skowronski, M. and Kuszko, W., Phys. Rev. Lett. 55 (1985) 2204.

[29] Samuelson, L., Omling, P., Weber, E. R. and GrimmeIss, H. G., in Proceedings of the Conference on Semi-Insulating III-V Materials, KahNee-Ta, Oregon, 1984, edited by D. C. Look and J. A. Blakemore (Shiva Publishing Limited, Nantwich, Cheshire, England) 1985, p. 268.

[30] Weber, E. R., ENNEN, H., KaufMaNN, U., WINDSCHEIF, J., SCHNEIDER, J. and WosinSKI, T., J. Appl. Phys. 53 (1982) 6140.

[31] The argument here is that if $\varepsilon_{\mathrm{i}}(2,0)$ were below the $\varepsilon_{\mathrm{a}}(1,0)$ level at $0.52 \mathrm{eV}$, the added charge $\Delta Q_{\mathrm{i}}$ on the $A s_{\mathrm{i}}$ would pull the $\varepsilon_{\mathrm{a}}(1,0)$ level down by an additional $\Delta Q_{\mathrm{i}} / 2 \varepsilon b$. The spacing between $\varepsilon_{\mathrm{a}}(2,1)$ and $\varepsilon_{\mathrm{a}}(1,0)$ would then be $U_{\mathrm{a}}+\Delta Q_{\mathrm{i}} / 2 \varepsilon b$, far larger than is observed.

[32] Blakemore, J. S., J. Appl. Phys. 53 (1982) R123.

[33] This level would lie below the strictly effective mass donor energy of $6 \mathrm{meV}$ in GaAs because the central cell corrections to this donor level will be attractive. In fact, the closer that $\varepsilon_{\mathrm{i}}(3,2)$ approaches the conduction band edge from above, the more attractive the central cell correction will become and the lower will be the energy of the Coulomb induced donor level.

[34] Watkins, G. D., in Lattice Defects in Semiconductors - 1974 Ed. F. A. Huntley, Institute of Physics Conference Series No. 23 (The Institute of Physics, Bristol and London) 1976, p. 1.

[35] Samuelson, L. and OMling, P., in Proc. 18th International Conference on the Physics of Semiconductors, Stockholm, Sweden 1986, edited by Olof Engstrom, p. 931.

[36] Levinson, M. and Kafalas, J., Phys. Rev. B 35 (1987) 9383.

[37] Scheffler, M. and Bachelet, G. B., in Proc. 13th International Conference on Defects in Semiconductors, Coronado California 1984, edited by L. C. Kimerling and J. M. Parsey Jr. (AIME) p. 45.

[38] Bourgoin, J. and Lannoo, M., Point Defects in Semiconductor, Vol. II, Springer Series in Solid State Sciences 35 (Springer-Verlag New York) 1983. 